\title{
Capturing the transcription factor interactome in response to sub-lethal insecticide exposure
}

\author{
Victoria A Ingham ${ }^{1, \#, *}$, Sara Elg ${ }^{1}$, Sanjay C Nagi ${ }^{1}$, Frank Dondelinger ${ }^{2}$ \\ ${ }^{1}$ Vector Biology, Liverpool School of Tropical Medicine, Pembroke Place, Liverpool, L35QA \\ ${ }^{2}$ Centre for Health Informatics, Computation and Statistics, Lancaster Medical School, Lancaster University, Bailrigg, Lancaster, LA1 4YE
}

\section{A R T I C L E I N F O}

\section{Keywords:}

Insecticide resistance

transcriptional response

transcription factors

Bayesian

time course

Anopheles

pesticide resistance

transcriptomics

\begin{abstract}
A B S T R A C T
The increasing levels of pesticide resistance in agricultural pests and disease vectors represents a threat to both food security and global health. As insecticide resistance intensity strengthens and spreads, the likelihood of a pest encountering a sub-lethal dose of pesticide dramatically increases. Here, we apply dynamic Bayesian networks to a transcriptome time-course generated using sub-lethal pyrethroid exposure on a highly resistant Anopheles coluzzii population. The model accounts for circadian rhythm and ageing effects allowing high confidence identification of transcription factors with key roles in pesticide response. The associations generated by this model show high concordance with lab-based validation and identifies 44 transcription factors putatively regulating insecticide-responsive transcripts. We identify six key regulators, with each displaying differing enrichment terms, demonstrating the complexity of pesticide response. The considerable overlap of resistance mechanisms in agricultural pests and disease vectors strongly suggests that these findings are relevant in a wide variety of pest species.
\end{abstract}

\section{Introduction}

Insecticides are critical for control of pests in agriculture and disease vectors in public health. The intensive and widespread use of insecticides in each of these settings has led to extensive insecticide resistance (WHO 2020), which poses a threat to both food security and global health. Vector borne diseases account for more than $17 \%$ of all infectious diseases annually (WHO 2020), whilst around 35\% of crops are lost to pre-harvest pests, underlining the importance of pesticide chemistries in global health and food security (Popp et al., 2013). Malaria control highlights the pivotal role of insecticides in global health with over $80 \%$ of the reductions in malaria cases since the turn of the century attributed to their use (Bhatt et al., 2015). Malaria control relies heavily on the distribution and use of insecticide treated bed nets (ITNs), which provide protection to the user and wider community protection through insecticide induced mortality of the adult Anopheles vectors (Hawley et al., 2003, Killeen and Smith, 2007, Killeen et al., 2011). All ITNs currently in use contain the pyrethroid class of insecticide; a fast-acting chemistry that induces immediate knockdown and mortality in susceptible mosquitoes. However, strength of resistance to pyrethroids is now such that populations of Anopheles can survive exposure with minimal effect on their life span (Hughes et al., 2020). Surviving sub-lethal exposures to pesticides is likely to have large and sustained consequences on the biology of the pest species.

Resistance to insecticides both in agricultural pests and disease vectors have been attributed to three characterised mechanisms; changes to the insecticide target site (Weill et al., 2004, MartinezTorres et al., 1998), thickening of the cuticle to reduce penetrance (Balabanidou et al., 2016) and metabolic clearance through overexpression of detoxification protein families (Müller et al., 2008, Voice et al., 2015, Ingham et al., 2018). Recently, new resistance mechanisms have been reported (Ingham et al., 2018, Ingham et al., 2019) and sublethal exposure has been shown to induce large-scale transcriptomic changes, highlighting the complexity of the insects response to insecticides (Ingham et al., 2020).

The demonstration of large-scale changes in transcriptome postexposure emphasises the importance of transcriptional control in response to insecticide. Despite this, the induction of genes in response to insecticides is poorly studied and the regulatory processes underlying these mechanisms have remained elusive. In most important pests, cis or trans-acting regulatory elements are yet to be identified, and little published research has focused on the role of the non-coding regulatory machinery. Although recent work has identified transcription factors involved in insecticide resistance such as two transcriptional

\footnotetext{
* Corresponding author

E-mail addresses: victoria.ingham@med.uni-heidelberg.de (V.A. Ingham), sara.elg@lstmed.ac.uk (S. Elg), sanjay.nagi@lstmed.ac.uk (S.C. Nagi),
} fdondelinger.work@gmail.com (F. Dondelinger).

\# Present address Centre for Infectious Diseases, Parasitology, Heidelberg University Hospital, Im Neuenheimer Feld 324, 69120 Heidelberg, Germany 
pathways: the Nrf2-cnc pathway in both disease vectors (Ingham et al., 2017, Bottino-Rojas et al., 2018) and agricultural pests (Kalsi and Palli, 2015, Gaddelapati et al., 2018) and the ARNT-AhR in agricultural pests (Peng et al., 2017, Hu et al., 2019), no studies in either setting have examined transcriptional response in a holistic manner. The availability of transcriptomic time-series data from resistant Anopheles coluzzii mosquitoes post-pyrethroid exposure (Ingham et al., 2020) has provided a resource to examine the importance of multiple transcription factors in response to insecticide.

Elucidating complex gene networks from transcriptomic time course data is a fundamental problem in computational systems biology (Delgado and Gómez-Vela, 2019, Thompson et al., 2015, Jackson et al., 2020). Time course data enables measurements of mRNA levels postperturbation and allows identification of transcripts following similar expression patters over time. Measuring changes in mRNA levels acts as a proxy for protein expression, but regulatory relationships cannot be captured by correlation alone, due to the presence of indirect regulation (gene A regulates gene $\mathrm{B}$ which regulates gene $\mathrm{C}$ ), and post-transcriptional changes. To allow reconstruction of gene regulatory networks, dynamic Bayesian networks have successfully been applied to real-world time course studies (Murphy and Mian, 1999, Dondelinger et al., 2013, Dondelinger and Mukherjee, 2019), allowing identification of key regulatory pathways within a system. These models additionally allow correction for confounding factors. For example, as circadian rhythms can play a significant role in gene expression patterns over short time-scales (Rund et al., 2011), sinusoidal patterns with 24-hour period may be corrected for.

Here, we apply a modified dynamic Bayesian network method to whole-organism microarray data taken at ten time-points post exposure to a pyrethroid insecticide. The method corrects for both circadian patterns and mosquito ageing, which have previously been shown to be important in the insecticide resistance phenotype (Jones et al., 2012, Rund et al., 2016). The Bayesian network approach allows identification of key regulatory factors influencing the expression of transcripts in response to insecticide exposure. Based on validation experiments, we estimate that the inferred network has $70 \%$ precision, indicating strong concordance of experimental data to model prediction. The network is made freely available through a ShinyR application, allowing non-bioinformaticians to easily access and visualise the data. Several transcription factors are highlighted as potential key regulators in response to pyrethroid insecticide. This study demonstrates the importance and complexity of transcriptional control of insecticide response, which is likely to have cross species applicability due to relative conservation of transcriptional pathways (Hsia and McGinnis, 2003) and near total overlap of resistance mechanisms.

\section{Results}

\section{Identification of transcription factors involved in insecticide resistance}

Of the transcripts in the Anopheles microarray, approximately 4\% are putative transcription factors, based on FlyMine.org AGAP homologs of Drosophila transcription factors found on FlyTF.org. As exploration of all possible transcription factor/transcript associations was not computationally feasible, the number of transcription factors had to be reduced to $<50$. Of the 559 total transcription factors, 44 were used in further analyses (Table 1). These transcription factors were selected based on resistance-associated GO term enrichments in transcription factor-transcript clusters (Zhang et al., 2018) found using a previously published library of microarray data comparing resistant and susceptible Anopheles species across Africa (Ingham et al., 2018). A number of these transcription factors have known roles in stress response in Drosophila (Table 1); however, only Maf-S, Met and Dm have previously been linked with insecticide response in mosquitoes (Ingham et al., 2018, Ingham et al., 2017). Of the transcription factors selected for analysis the following have been studied in mosquitoes: $p 53$ has been shown to respond to arboviral infection (Chen et al., 2017); Rbsn-5 has been shown to be involved in egg shell formation (Amenya et al., 2010); $l(1) s c$ is linked with sensory tissue development (Wülbeck and Simpson, 2002); kayak is involved in salivary gland response to arboviral infection through $J N K$ pathway activation (Chowdhury et al., 2020); Hnf4 is linked to ecdysone and Met mediated lipid metabolism (Wang et al., 2017); Cyc controls the circadian ryhthm (Maliti et al., 2016); REL1 and REL2 are involved in immune response (Luna et al., 2006); $K r-h 1$ is essential for egg development (Fu et al., 2020) and Pan is linked with chromatin changes upon Plasmodium infection (Ruiz et al., 2019).

\section{Modelling the insecticide response network}

To explore the role of the identified transcription factors in insecticide response, a previously generated time course experiment comparing pyrethroid exposed and unexposed Anopheles coluzzii was used (Ingham et al., 2020). This dataset was then used to model the gene regulatory relationships using a dynamic Bayesian network (DBN) approach (Dondelinger et al., 2013) which infers the regulators of each transcript from the set of selected transcription factors using the timecourse of log-fold changes compared to the unexposed baseline measurement, correcting for ageing and circadian rhythms. A Markov chain Monte Carlo (MCMC) algorithm was used to draw samples from the posterior distribution of the network model given the data, and associations were then ranked between target genes and transcription factors using the marginal posterior probability of the corresponding edge (defined as a predicted transcription factor - transcript association) in the network. Since experimental validation of all discovered edges is prohibitively expensive, an important consideration was how many associations needed to be tested in order to establish the validity of the network inference approach. A simulation study was performed under the assumption that the number of genes regulated by each transcription factor follows a Poisson distribution with parameter $\lambda=10$. We showed that under some assumptions (see Materials and Methods) testing 4 regulatory relationships for each of 7 transcription factors has a $70 \%$ chance of obtaining an estimate of the precision that falls within $10 \%$ of the true precision, and a $95 \%$ chance of obtaining an estimate that falls within $20 \%$ of the true precision. For 5 transcription factors with 4 regulatory relationships, this still gives a $65 \%$ chance of an estimate within $10 \%$, and a $90 \%$ chance of an estimate within $20 \%$ of the true precision.

The model was validated using quantitative PCR to confirm the interactions predicted by the model. Successful dsRNA mediated knock down was performed on 5 transcription factors, these showed knock down 48-hours post insecticide exposure (Supplementary Figure 1); the single time point used for model confirmation (Supplementary Figure 1, Supplementary Table 1). Four transcript interactors were chosen randomly for each transcription factor based on a posterior probability of $>0.1$. To determine the change in transcript expression post-exposure and to determine whether predicted interactors were influenced by the knock down of the stated transcription factor 2 comparisons were made: (i) GFP-injected exposed vs GFP-injected unexposed and (ii) Exposed transcription factor knockdown compared to exposed GFP-injected for the two comparisons respectively (Supplementary Table 1). Of the 16 interactors ( 4 transcription factors $\mathrm{x} 4$ interactors), 11 demonstrated concordance with the model, showing a substantial change in expression due to transcription factor knockdown, indicating $69 \%$ model precision (Figure 2, Supplementary Table 1).

\section{Network Overview}

In order to determine what the optimal cut-off for the marginal posterior probability values should be, a permutation test was performed whereby the observed log-fold values for one of the 44 transcription factors are randomly permuted, so that the original time associations were 
Table 1

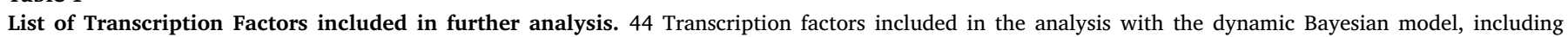

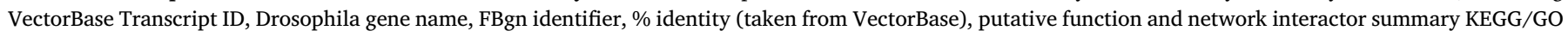
enrichment from this study (See S1 Table 1).

\begin{tabular}{|c|c|c|c|c|c|c|}
\hline Transcript ID & Gene Name & Homolog & \% Identity & Role in Drosophila & Citation & Network Enrichment \\
\hline AGAP000057-RA & shaven (sv) & FBgn0005561 & 34.12 & Sensory tissue development & $\begin{array}{l}\text { Kavaler et al. } 1999 \\
\text { (Kavaler et al., 1999) }\end{array}$ & None \\
\hline AGAP000066-RA & Sox102F & FBgn0039938 & & $\begin{array}{l}\text { Neuronal development, } \\
\text { behaviour and Wnt signalling }\end{array}$ & Li et al. 2017 (Li et al., 2017) & $\begin{array}{l}\text { mTOR and ECM-receptor } \\
\text { interaction }\end{array}$ \\
\hline AGAP000141-RA & CG31224 & FBgn0051224 & 17.03 & Unknown & & Nuclear-related \\
\hline AGAP000547-RA & Rbsn-5 & FBgn0261064 & 42.29 & Endosome assembly & $\begin{array}{l}\text { Morrison et al 2008 } \\
\text { (Morrison et al., 2008) }\end{array}$ & Polarity, Wingless \\
\hline AGAP000646-RA & $\begin{array}{l}\text { Diminuitive (Dm, } \\
\text { dMyc) }\end{array}$ & FBgn0262656 & 13.21 & $\begin{array}{l}\text { Glucose and lipid } \\
\text { metabolism, development }\end{array}$ & $\begin{array}{l}\text { Parisi et al. } 2013 \\
\text { (Parisi et al., 2013) }\end{array}$ & $\begin{array}{l}\text { Sugar Metabolism, } \\
\text { Miscellaneous Metabolism }\end{array}$ \\
\hline AGAP000876-RA & $\begin{array}{l}\text { achaete-scute } \\
\text { complex (l(1)sc) }\end{array}$ & FBgn0002561 & 26.42 & $\begin{array}{l}\text { Neuronal development, } \\
\text { dopaminergic neurons }\end{array}$ & $\begin{array}{l}\text { Stagg et al } 2011 \text { (Stagg et al., } \\
\text { 2011) }\end{array}$ & $\begin{array}{l}\text { Cuticle-related, Neuroactive } \\
\text { ligand-receptor }\end{array}$ \\
\hline AGAP001093-RA & kayak (kay) & FBgn0001297 & 30.06 & $\begin{array}{l}\text { JNK signalling, wound } \\
\text { healing, neuronal } \\
\text { development }\end{array}$ & $\begin{array}{l}\text { Ramet et al. } 2002 \\
\text { (Rämet et al., 2002); Miotto } \\
\text { et al. } 2006 \text { (Miotto et al., } \\
\text { 2006) }\end{array}$ & RNA/DNA-related Processes \\
\hline AGAP001156-RA & $\begin{array}{l}\text { PSEA-binding } \\
\text { protein } 95 \mathrm{kD} \\
(\mathrm{Pbp} 95)\end{array}$ & FBgn0037540 & 13.89 & $\begin{array}{l}\text { Small nuclear RNA activating } \\
\text { complex }\end{array}$ & Li et al 2004 (Li et al., 2004) & $\begin{array}{l}\text { Cytochrome P450s, } \\
\text { Signalling Pathways }\end{array}$ \\
\hline AGAP001388-RA & $\begin{array}{l}\text { Doublesex-Mab } \\
\text { related 93B } \\
(\mathrm{dmrt93B})\end{array}$ & FBgn0038851 & 41.61 & Mouth development & $\begin{array}{l}\text { Panara et al } 2019 \\
\text { (Panara et al., 2019) }\end{array}$ & $\begin{array}{l}\text { Taste/sense-related, } \\
\text { Oxidoreductase Activity }\end{array}$ \\
\hline AGAP001786-RA & Osa & FBgn0261885 & 36.83 & EGFR signalling & $\begin{array}{l}\text { Terriente-Feliz and de Celis } \\
2009 \text { (Terriente-Félix and de } \\
\text { Celis, 2009) }\end{array}$ & GSTs \\
\hline AGAP001994-RA & $\begin{array}{l}\text { Brahma associated } \\
\text { protein } 111 \mathrm{kD} \\
\text { (Bap111) }\end{array}$ & FBgn0030093 & 40.1 & Chromatin remodelling & $\begin{array}{l}\text { Papoulas et al. } 2001 \\
\text { (Papoulas et al., 2001) }\end{array}$ & $\begin{array}{l}\text { Miscellaneous Metabolism, } \\
\text { Cytochrome P450s, COEs }\end{array}$ \\
\hline AGAP002082-RA & Squeeze (sqz) & FBgn0010768 & 35.47 & Neuronal development & $\begin{array}{l}\text { Terriente-Feliz et al } 2007 \\
\text { (Félix et al., 2007) }\end{array}$ & Ligase Activity \\
\hline AGAP002155-RA & $\begin{array}{l}\text { Hepatocyte nuclear } \\
\text { factor } 4(\mathrm{Hnf} 4)\end{array}$ & FBgn0004914 & 52.85 & $\begin{array}{l}\text { Lipid mobilisation, glucose } \\
\text { homeostasis and } \\
\text { mitochondrial function }\end{array}$ & $\begin{array}{l}\text { Palanker et al. } 2009 \\
\text { (Palanker et al., 2009); Barry } \\
\text { and Thummel } 2016 \\
\text { (Barry and Thummel, 2016) }\end{array}$ & $\begin{array}{l}\text { Glyoxylate Metabolism, } \\
\text { Transcription Coactivator }\end{array}$ \\
\hline AGAP002352-RB & p53 & FBgn0039044 & 14.2 & Genotoxic stress response & $\begin{array}{l}\text { Brodsky et al. } 2004 \\
\text { (Brodsky et al., 2004) }\end{array}$ & Carbon metabolism \\
\hline AGAP002773-RA & Stripe (sr) & FBgn0003499 & & Muscle development & $\begin{array}{l}\text { Lee et al. } 1995 \text { (Lee et al., } \\
\text { 1995) }\end{array}$ & Steroid biosynthesis \\
\hline AGAP002902-RA & Medea (Med) & FBgn0011655 & 52.42 & $\begin{array}{l}\text { Muscle development through } \\
\text { BMP and dpp Pathways }\end{array}$ & $\begin{array}{l}\text { Wisotzkey et al. } 1998 \\
\text { (Wisotzkey et al., 1998) }\end{array}$ & Metabolism-related \\
\hline AGAP002920-RA & CG17829 & FBgn0025635 & 17.84 & Unknown & & $\begin{array}{l}\text { Protein Complex Binding, } \\
\text { DNA/RNA processes }\end{array}$ \\
\hline AGAP002954-RA & $\begin{array}{l}\text { Cell division cycle } 5 \\
\text { (Cdc5) }\end{array}$ & FBgn0035136 & 63.63 & Spliceosome & $\begin{array}{l}\text { Herold et al. } 2009 \\
\text { (Herold et al., 2009) }\end{array}$ & Notch Signalling, Apoptosis \\
\hline AGAP003117-RA & Capicua (cic) & FBgn0262582 & 19.37 & $\begin{array}{l}\text { EGFR, Torso and TOLL } \\
\text { signalling }\end{array}$ & $\begin{array}{l}\text { Astigarraga et al. 2007 } \\
\text { (Astigarraga et al., 2007); } \\
\text { Papagianni et al.2018 } \\
\text { (Papagianni et al., 2018) }\end{array}$ & Glycan degradation \\
\hline AGAP003449-RA & Rootletin (Root) & FBgn0039152 & 46.08 & Hearing, touch and taste & $\begin{array}{l}\text { Chen et al. } 2015 \text { (Chen et al., } \\
\text { 2015) }\end{array}$ & $\begin{array}{l}\text { Steroid Biosynthesis, } \\
\text { Receptor-related activity, } \\
\text { Cytochrome P450s }\end{array}$ \\
\hline AGAP003669-RA & Drop (Dr) & FBgn0000492 & 61.4 & Eye and nerve development & $\begin{array}{l}\text { Tearle et al. } 1994 \\
\text { (Tearle et al., 1994) }\end{array}$ & Circadian Pathway \\
\hline AGAP004864-RA & $\begin{array}{l}\text { Protein on ecdysone } \\
\text { puffs (Pep) }\end{array}$ & FBgn0004401 & 38.87 & $\begin{array}{l}\text { Hsp70 response through } \\
\text { hnRNP complex }\end{array}$ & $\begin{array}{l}\text { Hamann et al. } 1998 \\
\text { (Hamann and } \\
\text { Strätling, 1998) }\end{array}$ & Response to xenobiotics \\
\hline AGAP004990-RA & $\begin{array}{l}\text { Multiprotein } \\
\text { bridging factor } 1 \\
\text { (mbf1) }\end{array}$ & FBgn0262732 & 74.15 & $\begin{array}{l}\text { Co-activator to induce } \\
\text { stress-response genes }\end{array}$ & $\begin{array}{l}\text { Jindra et al. 2004 } \\
\text { (Jindra et al., 2004) }\end{array}$ & Translation-related Processes \\
\hline AGAP005437-RA & $\begin{array}{l}\text { Inverted repeat } \\
\text { binding protein } 18 \\
\mathrm{kDa}(\mathrm{Irbp} 18)\end{array}$ & FBgn0036126 & & $\begin{array}{l}\text { Inhibitor of the conserved } \\
\text { stress response protein } \\
\text { dATF4/Crc }\end{array}$ & $\begin{array}{l}\text { Blanco et al } 2020 \\
\text { (Blanco et al., 2020) }\end{array}$ & Fatty Acid-related \\
\hline AGAP005551-RA & $\begin{array}{l}\text { Rabaptin-5- } \\
\text { associated exchange } \\
\text { factor for Rab5 } \\
\text { (Rabex-5) }\end{array}$ & FBgn0262937 & 37.75 & Ras pathway homeostasis & $\begin{array}{l}\text { Yan et al. } 2010 \text { (Yan et al., } \\
\text { 2010) }\end{array}$ & Apoptosis \\
\hline AGAP005641-RA & CG9705 & FBgn0036661 & 54.78 & Sensory neurons & $\begin{array}{l}\text { Iyer et al. } 2013 \text { (Iyer et al., } \\
\text { 2013) }\end{array}$ & $\begin{array}{l}\text { Protein Sorting, Response to } \\
\text { DNA-damage }\end{array}$ \\
\hline AGAP005655-RA & Cylce (Сyc) & FBgn0023094 & 35.25 & Circadian rhythm & $\begin{array}{l}\text { Rutila et al. } 1998 \\
\text { (Rutila et al., 1998) }\end{array}$ & UGTs, Hormone Biosynthesis \\
\hline AGAP006022-RA & $\begin{array}{l}\text { Methoprene tolerant } \\
\text { (Met) }\end{array}$ & FBgn0002723 & 21.2 & Juvenile hormone binding & $\begin{array}{l}\text { Jindra et al. } 2015 \\
\text { (Jindra et al., 2015) }\end{array}$ & Oxidative Phosphorylation \\
\hline AGAP006061-RA & Ken & FBgn0000286 & 5.92 & JAK/STAT pathway & $\begin{array}{l}\text { Arbouzova et al. } 2006 \\
\text { (Arbouzova et al., 2006) }\end{array}$ & $\begin{array}{l}\text { GTPase Activity, } \\
\text { Vesicle-related, Actin-related }\end{array}$ \\
\hline
\end{tabular}


Table 1 (continued)

\begin{tabular}{|c|c|c|c|c|c|c|}
\hline Transcript ID & Gene Name & Homolog & $\%$ Identity & Role in Drosophila & Citation & Network Enrichment \\
\hline AGAP006392-RA & CG4617 & FBgn0029936 & 38.58 & Unknown & & Autophagy \\
\hline AGAP006601-RA & MEP-1 & FBgn0035357 & 31.69 & Chromatin remodelling & $\begin{array}{l}\text { Reddy et al. } 2010 \\
\text { (Reddy et al., 2010) }\end{array}$ & Peroxisome, CSPs \\
\hline AGAP006642-RA & $\begin{array}{l}\text { Defective } \\
\text { proventriculus (dve) }\end{array}$ & FBgn0020307 & 47.98 & $\begin{array}{l}\text { Mitochondrial reactive } \\
\text { oxygen species modulator }\end{array}$ & $\begin{array}{l}\text { Baqri et al. } 2014 \text { (Baqri et al., } \\
\text { 2014) }\end{array}$ & $\begin{array}{l}\text { Behavioural-related, } \\
\text { Neuron-related }\end{array}$ \\
\hline AGAP006736-RA & Sugarbabe (sug) & FBgn0033782 & 28.24 & $\begin{array}{l}\text { Regulation of lipid and } \\
\text { carbohydrate metabolism }\end{array}$ & $\begin{array}{l}\text { Varghese et al. 2010 } \\
\text { (Varghese et al., 2010) }\end{array}$ & P450, IMD-pathway \\
\hline AGAP006747-RA & Relish (REL2) & FBgn0014018 & 24.12 & Immune response & $\begin{array}{l}\text { Dushay et al. } 1996 \\
\text { (Dushay et al., 1996) }\end{array}$ & $\begin{array}{l}\text { Transferase, } \\
\text { Dendrite-related, CSPs }\end{array}$ \\
\hline AGAP009444-RA & $\begin{array}{l}\text { Suppressor of } \\
\text { variegation } 205 \\
(\mathrm{Su}(\mathrm{var}) 205)\end{array}$ & FBgn0003607 & 23.47 & $\begin{array}{l}\text { Hsp70 response through } \\
\text { activation of euchromatic } \\
\text { genes }\end{array}$ & $\begin{array}{l}\text { Piacentini et al. } 2003 \\
\text { (Piacentini et al., 2003) }\end{array}$ & $\begin{array}{l}\text { Ribosome-related, Hippo } \\
\text { signalling }\end{array}$ \\
\hline AGAP009494-RA & Ets at $21 \mathrm{C}$ (Ets21C) & FBgn0005660 & 34.25 & $\begin{array}{l}\text { Stress inducible transcription } \\
\text { factor through JNK }\end{array}$ & $\begin{array}{l}\text { Mundorf et al. 2019 } \\
\text { (Mundorf et al., 2019) }\end{array}$ & $\begin{array}{l}\text { Behaviour-related, Neuronal, } \\
\text { JAK/STAT }\end{array}$ \\
\hline AGAP009515-RA & REL1 & FBgn0260632 & 38.96 & Toll pathway & $\begin{array}{l}\text { Gross et al. } 1999 \\
\text { (Gross et al., 1999) }\end{array}$ & $\begin{array}{l}\text { Vesicle-related Transport, } \\
\text { Mitophagy, Toll pathway }\end{array}$ \\
\hline AGAP009662-RA & $\begin{array}{l}\text { Kruppel Homolog } 1 \\
\text { (Kr-h1) }\end{array}$ & FBgn0028420 & 36.47 & 20-hydroxyecdysone linked & $\begin{array}{l}\text { Pecasse et al. 2000 } \\
\text { (Pecasse et al., 2000) }\end{array}$ & TCA-cycle \\
\hline AGAP009676-RA & Chameau (chm) & FBgn0028387 & 34.66 & JNK signalling & $\begin{array}{l}\text { Miotto et al. } 2006 \text { (Miotto } \\
\text { et al., 2006) }\end{array}$ & $\begin{array}{l}\text { Transmembrane Signalling, } \\
\text { Behavioural-related, } \\
\text { Neuronal }\end{array}$ \\
\hline AGAP009888-RA & CG33695 & FBgn0052831 & 53.3 & Unknown & & Hippo Signalling, COEs \\
\hline AGAP009899-RA & klumpfuss (klu) & FBgn0013469 & 42.86 & $\begin{array}{l}\text { Cell death, mitochondrial } \\
\text { function, EGFR signalling }\end{array}$ & $\begin{array}{l}\text { Protzer etl al. } 2008 \\
\text { (Protzer et al., 2008); Chen } \\
\text { et al. } 2008 \text { (Chen et al., } \\
\text { 2008) }\end{array}$ & $\begin{array}{l}\text { Morphogenesis, Drug } \\
\text { Metabolism, UGTs, GSTs }\end{array}$ \\
\hline AGAP009983-RA & Net & FBgn0002931 & 35.88 & EGFR signalling & $\begin{array}{l}\text { Terriente-Feliz and de Celis } \\
2009 \text { (Terriente-Félix and de } \\
\text { Celis, 2009) }\end{array}$ & MAPK/Notch Signalling \\
\hline AGAP010405-RA & Maf-S & FBgn0034534 & 63.7 & $\begin{array}{l}\text { Reactive oxygen species } \\
\text { stress response }\end{array}$ & $\begin{array}{l}\text { Misra et al. } 2011 \\
\text { (Misra et al., 2011) }\end{array}$ & $\begin{array}{l}\text { Respiration-related, } \\
\text { Insulin-related }\end{array}$ \\
\hline AGAP012389-RA & Pangolin (Pan) & FBgn0085432 & 24.47 & Wingless signalling & $\begin{array}{l}\text { Brunner et al. } 1997 \\
\text { (Brunner et al., 1997) }\end{array}$ & Wnt-signalling, COEs \\
\hline
\end{tabular}

no longer present (Appendix 1). Any association between this transcription factor and the target gene would then be purely due to chance. This process was then repeated 500 times, inferring the edges for all 44 transcription factors each time. The resulting marginal posterior probability values were then analysed for the randomised transcription factor and showed that a threshold of 0.39 was sufficient to only produce one false positive out of 500 randomizations, or a false positive rate of 0.002 (Appendix 1), which resulted in assignment of 5136 transcripts to the 44 transcription factors.

The complete network using a posterior probability cut-off of 0.39 is displayed in Figure 1. Due to the constraints imposed by this model on number of parent nodes tested, simple network descriptive data was generated only for edges from the selected transcription factors. The average edge count was $118.48 \pm 179.62$ demonstrating high variance in connectivity as seen in Figure 1 with a range of 8 associations to 951. 23 transcription factors are network hubs, defined as nodes with a high number of associations $(>50)$ (Table 2), including $\mathrm{Dm}$, Met and Maf-S all previously linked with the insecticide resistance phenotype (Ingham et al., 2018, Ingham et al., 2017) and mbf1 a stress response transcription factor (Jindra et al., 2004). To enable the network to be freely accessible an application NetworkVis has been written in ShinyR (Chang et al., 2017) and is available online (https://github.com/VictoriaIngham/NetworkVis_TimeCourse; Supplementary Table 2) with all associated data. Users can manually select a posterior probability cut-off between $0.1-0.8$, select and rearrange nodes and edges in the network and identify a priori transcription factors through visual means rather than working with a large text file.

Enrichment analysis was run for every transcription factor and associated interactors for all GO term categories (Ashburner et al., 2000), KEGG pathways (Kanehisa and Goto, 2000), gene families previously associated with resistance (Balabanidou et al., 2016, Müller et al., 2008, Voice et al., 2015, Ingham et al., 2018, Ingham et al., 2019) and Re-
Table 2

Transcription factor hubs. Identifier, gene name and number of associations for 23 transcription factor hubs within the network.

\begin{tabular}{lll}
\hline Transcription Factor & Name & Number of associations \\
\hline AGAP009676-RA & Chm & 951 \\
AGAP001388-RA & dmrt93B & 535 \\
AGAP009444-RA & Su(var)205 & 447 \\
AGAP003449-RA & Root & 447 \\
AGAP009983-RA & Net & 399 \\
AGAP009494-RA & Ets21C & 227 \\
AGAP001994-RA & Bap111 & 201 \\
AGAP001156-RA & Pbp95 & 185 \\
AGAP002920-RA & CG17829 & 145 \\
AGAP009899-RA & Klu & 118 \\
AGAP005437-RA & Irbp18 & 113 \\
AGAP006392-RA & CG4617 & 98 \\
AGAP000646-RA & Dm & 91 \\
AGAP001093-RA & Kay & 87 \\
AGAP004990-RA & Mbf1 & 72 \\
AGAP006642-RA & Dve & 69 \\
AGAP005655-RA & Cyc & 66 \\
AGAP010405-RA & Maf-S & 64 \\
AGAP002155-RA & Hnf4 & 60 \\
AGAP006601-RA & Ken & 58 \\
AGAP000876-RA & l(1)sc & 57 \\
AGAP006022-RA & Met & 53 \\
AGAP002773-RA & Sr & 51 \\
\hline
\end{tabular}

actome pathways based on Drosophila homology (Jassal et al., 2020) (Table 1, Supplementary Table 3).

GO enrichments were present for 21/44 of the transcription factors across all ontology categories (Molecular Function, Cellular Component and Biological Process). A large number of GO terms were significant across different transcription factor interactions analysed; however, the terms were largely non-overlapping indicating that the transcription fac- 

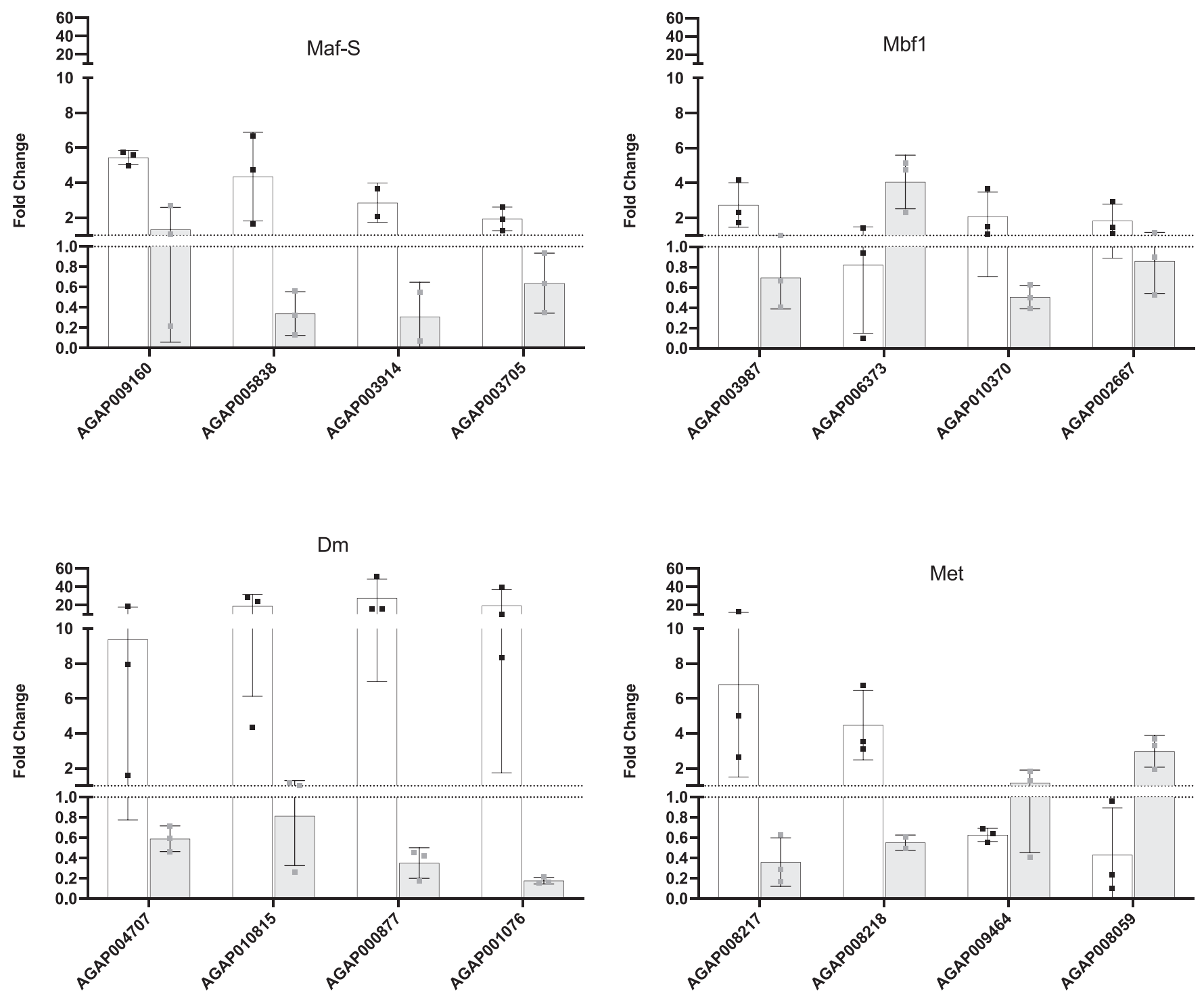

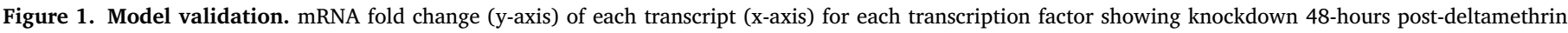

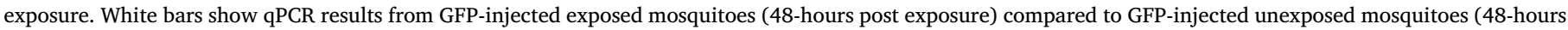

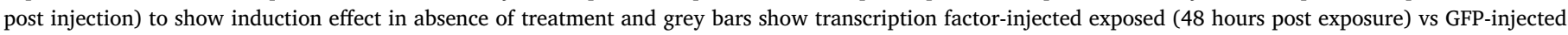
exposed mosquitoes (48-hours) to demonstrate the effect of transcription factor knockdown. Error bars show standard deviation.

tors are playing differing roles in insecticide response (Supplementary Table 3, Supplementary Figure 2). Seven GO terms (dendrite, dendritic tree, somatodendritic compartment, transmembrane signalling receptor activity, signalling receptor activity, response to drugs) were significant across four transcription factors and relate to terms clearly involved in stress response and associated behavioural changes.

KEGG enrichments were present for 39/44 transcription factors (Supplementary Table 3, Supplementary Figure 3), again there was minimal overlap in the enriched pathways, in agreement with the divergent enriched GO terms. One KEGG pathway was significant for six transcription factor associations (neuroactive ligand-receptor interaction) and two terms were significant for four transcription factor associations (insect hormone biosynthesis, other glycan degradation).

Given our a priori knowledge of insecticide resistance, enrichment analysis was also carried out for detoxification gene families, the cuticular hydrocarbon synthesis pathway and chemosensory proteins; three well described resistance mechanisms (Balabanidou et al., 2016, Müller et al., 2008, Voice et al., 2015, Ingham et al., 2019). Enrichments for these families occurred in 20/44 transcription factors with cytochrome p450s being significantly enriched in eight, GSTs in four, UGTs in three, COEs in eight, chemosensory proteins in two and the cuticular hydrocarbon pathway in three (Supplementary Table 3, Supplementary Figure 4). Reactome enrichment was also carried out, with significance for at least one pathway in 21/44 of the transcription factors (Supplementary Table 3, Supplementary Figure 5).

Taken together, these data indicate that the applied DBN is successfully capturing differing roles of the transcription factors in insecticide exposure response and the enrichment of a large number of a priori detoxification candidates indicates we are successfully capturing transcription factors controlling metabolic response to insecticide exposure.

\section{Key transcriptional regulators of insecticide response}

Transcription factors that have previously been implicated in insecticide resistance or stress response and those that have interactors which show a clear functional enrichment from the above analysis are described in greater detail below. 


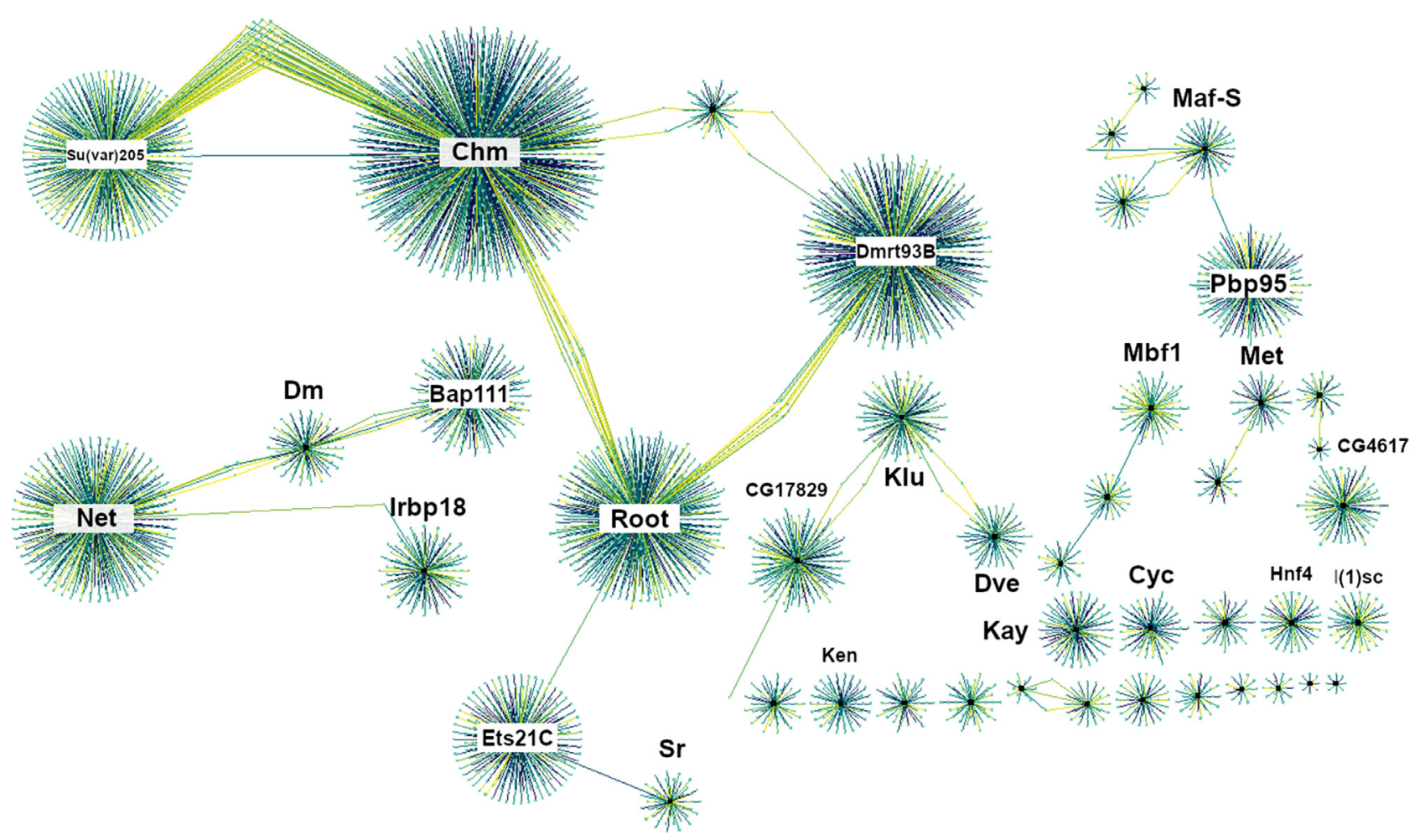

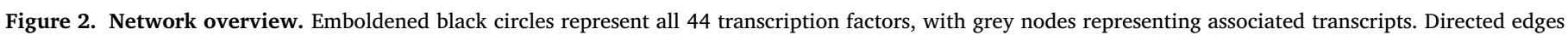

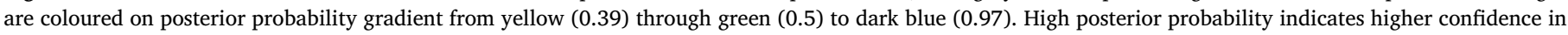
the interaction. The 23 hub transcription factors, with $>50$ associations are labelled.

\section{Chameau}

Chameau (Chm, AGAP009676-RA) is the transcription factor with the highest number of interactors at 951. Chm interactors are strongly enriched in transmembrane signalling activity $(\mathrm{p}=1.32 \mathrm{e}-8)$, sensory perception $(p=3.39 \mathrm{e}-6)$ and chemosensory behaviour $(\mathrm{p}=8.74 \mathrm{e}-4) .26$ other transcription factors interact directly with $\mathrm{Chm}$ including AbdB (AGAP004664-RA) including a known Drosophila interaction and so (AGAP011695-RA), Fer3 (AGAP003756-RA), disco (AGAP01106-RA), C15 (AGAP003674-RA), zfh1 (AGAP000779-RA), $h k b$ (AGAP004517), all known secondary interactors. 14 interactors have posterior probabilities of $>0.90$, including fringe (AGAP006439-RA) a gene involved in regulating the Notch signalling pathway (Moloney et al., 2000), which is significantly enriched in Chm interactors $(\mathrm{p}=0.012)$ and Roquin (AGAP007114-RA) a protein that translocates to stress granules on chemical induced toxicity (Athanasopoulos et al., 2010, Voßfeldt et al., 2012).

\section{Diminuitive}

Diminuitive (Dm, AGAP00646-RA) is a central network hub with 91 interactors and its interactors are enriched in multiple KEGG pathways such as $\mathrm{N}$-glycan biosynthesis, protein processing in the endoplasmic recticulum and starch and sucrose metabolism (Supplementary Table 3) (Martinez-Torres et al., 1998, Ingham et al., 2017, Nagy et al., 2013, Kappes et al., 2011). Previous work has demonstrated that attenuating Dm expression in An. gambiae results in significantly higher mortality post-pyrethroid exposure (Ingham et al., 2018); this role is underlined by significant enrichment of detoxification gene families in this cluster including the COEs $(\mathrm{p}=0.031)$ and $\mathrm{ABCs}(\mathrm{p}=7.2 \mathrm{e}-3)$ (Wilding et al., 2014, Riveron et al., 2014). Interestingly, the ABCs in this network belong to the $\mathrm{ABCB}$ family of transporters, which are known as multi-drug transporters and are implicated in insecticide resistance in Drosophila and Anopheles (Gellatly et al., 2015, Pignatelli et al., 2018). Dm also interacts with Bap111, whose network is enriched for fatty acid degradation and cuticular hydrocarbon synthesis and contains the cytochrome p450 CYP4G17, previously linked with cuticular thickening in resistant mosquitoes (Balabanidou et al., 2016). (Balabanidou et al., 2016)

\section{Doublesex-Mab related 93B}

Doublesex-Mab related 93B (dmrt93B, AGAP001388-RA) is the second most well-connected node with 535 interactors. Dmrt93B is enriched in multiple GO-terms related to xenobiotic metabolism, including oxidoreductase activity ( $\mathrm{p}=7.7 \mathrm{e}-3)$, heme-binding $(\mathrm{p}=2.6 \mathrm{e}-4)$ and monooxygenase activity $(\mathrm{p}=0.014)$ as well as being highly enriched in the a priori detoxification gene families; cytochrome $\mathrm{p} 450 \mathrm{~s}(\mathrm{p}=5.53 \mathrm{e}-6)$, COEs $(p=0.023)$ and GSTs $(p=0.029)$. Taken together, these enrichments indicate that $d m r t 93 B$ is playing a central role in the response of metabolic transcripts to insecticide exposure. Although not showing enrichment in a related term, 14 cuticular proteins are present in this interactome, one of which CPLCP11 (AGAP009758-RA) has been shown to be up-regulated in resistant mosquitoes compared to susceptible (Balabanidou et al., 2019) and another, CPR133 (AGAP009872-RA), has the highest posterior probability (0.93).

\section{Met and Maf-S}

Both Maf-S (AGAP010405-RA) and Met (AGAP006022-RA) have previously been shown to have important roles in insecticide response (Ingham et al., 2018, Ingham et al., 2017). In the absence of insecticide exposure, attenuation of expression of these transcripts demonstrated that both influenced the expression of key pyrethroid metabolisers such as CYP6M2, CYP6Z2, CYP6Z3, CYP6P4, GSTD1 and CYP9K1 (Yunta et al., 2019)(Ingham et al., 2017). Met interacts with CYP6Z2 which is amongst the most strongly induced p450s in the dataset with a marginal posterior probability of 0.88 . Interestingly, Maf-S shows enrichment in ABC transporters and terms related to ATP production, indicating Maf-S may play a role in changes in metabolism, which is a striking feature of this dataset. Met shows enrichment in glycolysis, potentially indicated an overlap in the function of these transcription factors, which would be in agreement with the Maf-S knockdown microar- 
ray which identified Met as a direct interactor. (Murata et al., 2015, Cornelissen et al., 2018)

\section{$M b f 1$}

Multiprotein bridging factor 1 ( $m b f 1$, AGAP004990) has 119 interactors and is enriched for GO terms related to the ribosome $(p=0.026)$ and RNA binding $(\mathrm{p}=0.048)$ and is highly enriched in the KEGG ribosome $(\mathrm{p}=4 \mathrm{e}-4)$. The role of $m b f 1$ in Drosophila involved translocation to the nucleus upon cellular stress, where it serves as a co-activator of stress response genes (Jindra et al., 2004); despite this role no enrichment for detoxification transcripts is seen in the predicted $m b f 1$ associations. However, 1 chaperone protein (CCT6) and an oxidative stress sensing protein (AGAP000705-RA) are present in this network. AGAP002667 has the highest posterior probability in the network (0.84) and encodes the homolog of Drosophila Tctp which is necessary for genomic stability under genotoxic stress (Hong and Choi, 2013).

(Taylor-Wells et al., 2015, Zhong and Wu, 2004, Ng and Luo, 2004, Koch et al., 2008, Schaefer et al., 2001, Varghese et al., 2010, Musselman et al., 2018, Bharucha et al., 2008, Beller et al., 2010)

\section{Discussion}

In this study, we apply a dynamic Bayesian network approach to whole transcriptome time-course data post-sublethal exposure of $A n$. coluzzii to the pyrethroid insecticide deltamethrin (Ingham et al., 2020). The modified DBN model employed here allows correction for not only circadian rhythms, but also for mosquito ageing, a critical variable in the resistance status (Jones et al., 2012). Interactions predicted by this model were then validated in vivo, demonstrating high model confidence, with $70 \%$ precision. The high model precision and the overlapping biological functions with known transcription factors in Drosophila demonstrates the utility of this approach in assigning transcription factor function. Furthermore, this study highlights the potential for use of this methodology across multiple species of interest in which lower resolution time points are more feasible than those seen in model organism studies. Potential applications of this methodology could include exploring transcriptional regulation of pesticide response in other pest species or exposing the same species to additional stressors to distinguish between transcription factors involved in general and insecticide induced stress response.

In this study we highlight 44 transcription factors with putative roles in response to sublethal pesticide exposure, 41 of which have not previously been linked to insecticide resistance. Of the 6585 transcripts differential in the data set used, 5136 transcripts were assigned associations with these 44 transcription factors, using a posterior probability cut-off of $>0.39$. The assignment of $78 \%$ of the overall responsive transcripts is likely due to necessity of reducing the number of transcription factors to less than 50 transcripts and responsive transcripts being regulated by other mechanisms such as non-coding regulatory machinery. The transcription factors selected here for further analysis were identified by applying an SILGGM model (Zhang et al., 2018) to 28 insecticide resistant vs susceptible microarray datasets performed on the Anopheles gambiae species complex collated by Ingham et al. (Ingham et al., 2018) and exploring enrichments of co-correlated transcripts; this represents a confounding aspect of this methodology as these transcripts are constitutively overexpressed and not induced by insecticide exposure due to the nature of the transcriptomic designs.

Of the 44 transcription factors, 3 had previously been linked with insecticide resistance in Anopheles mosquitoes and just 11 had been previously studied in mosquito species in any context (Ingham et al., 2018, Ingham et al., 2017, Ruiz et al., 2019, Chen et al., 2017, Amenya et al., 2010, Wülbeck and Simpson, 2002, Chowdhury et al., 2020, Wang et al., 2017, Maliti et al., 2016, Luna et al., 2006, Fu et al., 2020). All but 4 of these transcription factors have a well-defined role in Drosophila. Using a posterior probability cut off of $>0.39$, the number of associations showed high levels of variation with an average edge count of
$118.48 \pm 179.62$, potentially demonstrating differential importance in insecticide response, with those transcription factors with a high number of edges or high network connectivity being more important. 23 transcription factors were designated as transcript 'hubs' based on high levels of network interconnectivity ( $>50$ edges).

Enrichment analysis was performed for all transcription factors in the network, using GO Terms, KEGG Pathway, Reactome and a priori transcript families with links to resistance. Interestingly, the overlap of enriched terms was low, indicating that each transcription factor may play a differing role in the response to insecticides. 20 transcription factors show enrichments in a priori gene families; this may be an unsurprising feature of this dataset given the obvious change in expression across multiple members of these families within this dataset and their documented importance in insecticide metabolism (Ingham et al., 2020). GO terms enriched across multiple transcription factors include terms expected in an insecticide response, response to drugs, drug metabolism, sensory perception of chemical stimuli and $\mathrm{ABC}$ transporters. The former two enrichment terms are in agreement with the well-established dogma that up-regulation of members of the cytochrome p450 class play a direct role in increasing the rate of insecticide metabolism (Ingham et al., 2018, Yunta et al., 2019). (Oliver and Brooke, 2016, Wang et al., 2016). Interestingly, changes to the respiratory pathway through alterations to the oxidative phosphorylation pathway also appears across multiple transcription factors and is a striking feature of this dataset (Ingham et al., 2020).

To cross-validate the function of these transcription factors, their known functions in the model organism Drosophila were explored. Despite the differences in hypotheses explored in this study and the available data in discerning Drosophila pathways, there were clear overlaps in transcription factor roles and associations. For example, $D m$ is known to play a role in lipid and glucose homeostasis in Drosophila (Parisi et al., 2013) and here, the associations are enriched in the KEGG pathways starch and sucrose metabolism; this is similar to dmrt93B which is involved (Palanker et al., 2009) mouth part development and is enriched in the GO term related to taste receptor activity (Panara et al., 2019). Several further transcription factors show overlap with Drosophila function, including Pep which is involved in stress response through activation of Hsp70 (Hamann and Strätling, 1998, Varghese et al., 2010), dve which is involved in reactive oxygen species modulation (Baqri et al., 2014), Ets21C which is a stress-inducible transcription factor (Mundorf et al., 2019), klumpfuss whose role is related to morphogenesis in the central nervous system (Melcher and Pankratz, 2005), REL1 which is implicated in the TOLL pathway (Gross et al., 1999, Murata et al., 2015) and Chm is a known modulator of the stress responsive JNK pathway with a role in sensory cell fate (Melcher and Pankratz, 2005). (Wang et al., 2017, Ruiz et al., 2019)

This study provides not only previously unreported transcription factors that are involved in the transcriptional response to pesticide exposure but demonstrates the utility of applying a model-based approach to lower-resolution time course data in ascertaining these associations. Here, six transcription factors and their interactomes were delineated as hub transcripts within the network, all of which have either been previously linked to resistance or stress response in Anopheles (Dm, Maf-S and Met) (Ingham et al., 2018, Ingham et al., 2017) or Drosophila (mbf1) (Jindra et al., 2004) or are highly significantly enriched for clear functions (chameau and dmrt93B). These transcription factors are likely to be involved in different facets of insecticide response and represent pathways that should be further explored. The modelling approach taken here, which accounts for both circadian patterns and ageing, two key determinants in pesticide resistance, can be applied widely to other pest or vector species. Using this approach will provide invaluable information on changes to pest biology post-pesticide exposure and will elucidate new pathways to characterise and target to tackle the ongoing threat of pesticide resistance. 


\section{Materials and Methods}

Microarray Experiments

Microarrays were taken from (Ingham et al., 2020) and consist of deltamethrin exposed mosquitoes compared to unexposed at the following time points post-exposure: 0 minutes, 30 minutes, 1 hour, 2 hours, 4 hours, 8 hours, 12 hours, 24 hours, 48 hours and 72 hours. To account for ageing effects, a twin time course was performed using age matched females that were unexposed to insecticide at the following time points: 8 hours, 12 hours, 24 hours, 48 hours and 72 hours. All mosquitoes within one experimental time course came from the same generation. Experimental data is available on exposure time course (E-MTAB-9422) and ageing time course (E-MTAB-9423). Analysis was performed as previously described.

\section{Transcription factor identification}

To identify relevant nodes for the Bayesian analysis, 28 microarray datasets encompassing resistant vs susceptible members of the Anopheles gambiae species complex were used from Ingham et al. 2018 (Ingham et al., 2018). A de-sparsified node-wise scaled lasso (Janková and van de Geer, 2017, Janková and van de Geer, 2018) implemented in the R package SILGGM (Zhang et al., 2018), was used to infer the gene network. This method employs L1-regularisation to preserve sparsity in the estimated network. For the L1-regularisation, the default value of the tuning parameter $\lambda$, was used: $\sqrt{ } \log (\mathrm{p}) / \mathrm{n}$, where $\mathrm{p}$ is the number of variables and $n$ is the number of samples. The resultant Gaussian graphical model produced a $14079 \times 14079$ file for every possible interaction in the transcriptome. Each interaction had an associated $\mathrm{p}$-value for precision (Supplementary Table 4). A cut-off value of $p \leq 0.1$ was used to filter all interactions to prevent loss of potentially interesting transcription factors due to the differing experimental design of the data set used. Annotated Drosophila transcription factors were downloaded from FlyTF (Adryan and Teichmann, 2006) (http://flytf.gen.cam.ac.uk/) and Anopheles homologs identified using FlyMine (Lyne et al., 2007) (https://www.flymine.org) using the analyse input box, and then selecting An. gambiae homologs, resulting in 559 putative transcription factors; all 559 were then extracted from the inferred network with all associated putative co-correlating transcripts. clusterProfiler (Yu et al., 2012) and AnnotationForge (Carlson and Pagès, 2019) were used to perform GO enrichments using an Anopheles database built from PEST/VectorBase (Giraldo-Calderón et al., 2014) on Biological processes on transcription factors with $>10$ interactors. Transcription factors enriched in the following character patterns were extracted: 'stress'; 'oxi'; 'lipid'; 'behaviour'; 'response'; 'fat'; 'sensory' and 'ATP' leading to 54 transcription factors. The terms were chosen based on previous knowledge of the resistant mechanisms present in $A n$. coluzzii mosquitoes as detailed in the introduction (Balabanidou et al., 2016, Müller et al., 2008, Voice et al., 2015, Ingham et al., 2018, Ingham et al., 2019, Ingham et al., 2020) and 'ATP' due to a striking change in metabolism observed in this data set (Ingham et al., 2020). The transcription factors were further filtered on at least $50 \%$ of the transcripts in the cluster generated by SILGGM being differentially expressed in at least 1 time point within the time course datasets with an adjusted $\mathrm{p}$ value of $\leq 0.05$. This procedure resulted in 44 transcription factors being retained. To estimate the impact of transcription factor choice on the network inference, target genes with a marginal posterior probability of $>0.75$ of having an association with at least one of the transcription factors in the dynamic Bayesian network analysis were selected and the model was re-run using a random selection for $25 \%$ of the transcription factors $(11 / 44)$. The difference in marginal probability of the associations was then analysed. As the majority of differences are $<0.2$, the 0.39 cut-off used here would still correctly identify the associations with $>0.75$ marginal posterior probability in the original analysis (Supplementary Figure 6).
Network reconstruction using Dynamic Bayesian Networks

Dynamic Bayesian networks (DBNs) (Dondelinger et al., 2013) were used to identify directed associations between the transcription factors and putative regulated genes. A dynamic Bayesian network defines a graphical model for the dynamics of time series data, where the gene expression $X_{i}(t)$ of gene i at time t depends on the gene expression $X_{j}(t)$ of all transcription factor genes $\mathrm{j}$ at time $t-\delta$. The relationship can be described by the following auto-regressive linear regression:

$X_{i}(t)=a_{0}+\sum_{j \in T F} a_{j} X_{j}(t-\delta)+\varepsilon$

where $\varepsilon N\left(0, \sigma_{i}^{2}\right), \wedge T$ Fistheseto $f$ indices representing the transcription factors. To impose regularisation, we assumed truncated Poisson priors on the number of regression parameters $a_{j}$ that are non-zero:

$P\left(s_{i} \vee \lambda\right) \propto \frac{\lambda^{s_{i}}}{s_{i} !} I\left(s_{i}<s_{\max }\right)$

where $s_{\max }$ is the maximum number of transcription factors regulating a single gene. We set $s_{\max }=5$. Conditional on $s_{i}$, the number of non-zero transcription factor-gene associations, the prior on the set of transcription factors for a given gene is simply a uniform distribution.

Inference of the network structure can be done via a Markov Chain Monte Carlo algorithm, with discrete moves allowing for adding and removing edges during the sampling. Convergence was assessed by running each MCMC chain twice from independent starting points and comparing the marginal posterior edge probability estimates. We ran the MCMC algorithm for 500,000 iterations, discarding the first quarter as burn-in, which ensured good convergence across all target genes. For full details on the model and inference procedure, please see Appendix 1 . Note that here we employ a simplified version of the model in (Dondelinger et al., 2013) which does not use a changepoint model or information sharing priors.

Prior to applying the network inference model, we pre-processed the log-fold change data by first averaging the values for genes with multiple probes to obtain one measurement per gene. We then employ LOESS estimation (Cleveland et al., 1992), a local regression method which fits low-degree polynomials to subsets of the data, to interpolate the time points at $t-\delta$, where we choose $\delta=0.5$ hours as the time interval. Interpolation is necessary, as the DBN method requires equal time intervals between each pair of measurements to estimate consistent associations.

We further extend the model to correct for circadian rhythms and ageing effects in the gene expression levels. For the circadian rhythm correction, we assume that all circadian rhythms have a period of 24 hours, and augment the design matrix $\mathbf{X}=\left\{X_{1}(t), \ldots, X_{p}(t)\right\}$ with two additional columns for the sine and cosine functions of a 24 -hour periodic signal:

$X_{\sin }(t)=\sin (2 \pi t / 24), X_{\cos }(t)=\cos (2 \pi t / 24)$

The resulting harmonic regression model with automatically correct for circadian rhythms, including under phase shift, by adding the periodic signal as a parent in the network, while non-periodic genes will remain unconnected to this signal.

Similarly, we add additional columns for the data arising from the ageing controls to correct for the effect of ageing. Note that here we only have data starting from 8 hours, so earlier time points will be uncorrected, and the corresponding values in the design matrix will be set to zero. The final autoregressive model looks as follows:

$X_{i}(t)=a_{0}+\sum_{j \in T F}\left\{a_{j} X_{j}(t-\delta)\right\}+b_{\text {sin }} X_{\text {sin }}(t)+b_{\text {cos }} X_{\text {cos }}(t)+c X_{i, \text { ageing }}(t)+\varepsilon$ where $X_{i, \text { ageing }}(t)$ is the log-fold change of the ageing controls.

We summarize the results of the DBN analysis using the marginal posterior probability of each transcription factor - target gene association, which can be calculated by obtaining samples from the converged Markov chain and averaging over the presence/absence status of each edge. In order to determine a sensible threshold for the marginal posterior probability that keeps the false discovery rate low, we implement 
the following permutation test to estimate the posterior probabilities under the null hypothesis of no associations: for each of $n=500$ iterations, we randomly permute the log-fold changes for one transcription factor. Any associations with the target gene should then be entirely by chance. Taking all $n=500$ samples of the null distribution obtained in this way, we determine that a threshold of 0.39 was sufficient to only produce one false positive out of 500 randomizations, or a false positive rate of 0.002 . Further detail of the model can be found in Appendix 1 . The network was displayed using Cytoscape (Shannon et al., 2003).

To estimate how the computational time needed scales with the number of transcription factors, we repeatedly selected 10 target genes and $p$ transcription factors, where $p \in(5,100)$. Network inference using EDISON was then performed on a computational cluster with two Intel Xeon E5-2660 v4s, which have 14 physical cores running @ 2.00GHz each, and 256 GB of RAM, and the resulting computational time is recorded. All MCMC chains for the network inference algorithm are run for 500,000 iterations (Supplementary Figure 7).

\section{NetworkVis App}

The NetworkVis app and associated data can be downloaded on Github (https://github.com/VictoriaIngham/NetworkVis_TimeCourse) and installed as described. ShinyR (Chang et al., 2017) was used to create a user interface, both VisNetwork (Almende et al., 2018) and igraph (Csardi and Nepusz, 2006) were used to allow dynamic selection of nodes and edges, and to display the network.

\section{Enrichment analysis}

Enrichment analysis was performed using clusterProfiler ( $Y u$ et al., 2012) and a custom Anopheles database produced using AnnotationForge (Carlson and Pagès, 2019). GO term and KEGG enrichments were performed using a Benjamini-Hochberg corrected $\mathrm{p}$ value cut-off of $\leq$ 0.05 with transcription factors $>10$ interactions. Clusters of each transcription factor were compared using the compareCluster function using default parameters, Benjamini-Hochberg correction and a full background geneset from org.Agambiae.eg.db built from the PEST assembly; these were then displayed using Cytoscape (Shannon et al., 2003). Enrichment analysis on individual gene families were performed using a hypergeometric test with the phyper function in R; significance was considered when $\mathrm{p} \leq 0.05$. Reactome analysis was also performed using a hypergeometric test with $\mathrm{p} \leq 0.05$; Drosophila pathway membership was downloaded from Reactome.org (https://reactome.org/) (Jassal et al., 2020) for each pathway of interest, FlyMine (Lyne et al., 2007) was then used to convert these to Anopheles homologs. FlyBase (Consortium, 2003) was used to determine functions of homologs throughout the analysis. We applied the Benjamini-Hochberg correction for multiple testing outputs of the hypergeometric test.

\section{Validation of Network}

We first performed a simulation study to determine the number of associations that need to be tested experimentally in order to obtain an accurate estimate of the precision of our network inference method. We made the following assumptions: (i) The mean number of gene regulated by each transcription factor is 10 , and the actual number of regulated genes follows a Poisson distribution; (ii) The rate of true positives (correctly predicted associations) of our network is 0.75 , and the rate of true negatives (correctly predicted non-associations) is 0.997; this results in a precision of $\sim 0.56$ and a recall of $\sim 0.72$ (Appendix 2); (iii) Transcription factors and regulated genes to test are selected randomly and (iv) The qPCR knockdown test is $100 \%$ accurate. The results of the simulation study can be found in Appendix 2. We concluded that testing 4 regulatory relationships for 7 transcription factors has a $70 \%$ chance of obtaining an estimate of the precision that falls within $10 \%$ of the true precision, and a $95 \%$ chance of obtaining an estimate that falls within $20 \%$ of the true precision.

In order to choose associations for validation, we then chose interactors by extracting the transcription factor of interest and associated transcripts from the results of the network inference. Transcripts were listed as 1 to $\mathrm{n}$ based on posterior probability in descending order. A random number generator was then used to select 4 transcripts for validation from 6 transcription factors chosen based on previous knockdown in the case of Maf-S, Met, Dm or through a random number generator.

\section{Mosquito Rearing}

The An. coluzzii VK7 colony reared and profiled at Liverpool School of Tropical Medicine were used for all experiments (Williams et al., 2019). VK7 are a highly pyrethroid resistant population originating from Vallée de Kou, Burkina Faso (Toé et al., 2015). They have been reared at LSTM since 2014 under pyrethroid selection pressure (Williams et al., 2019). All mosquitoes used were reared under standard insectary conditions of $27^{\circ} \mathrm{C}$ and $70-80 \%$ relative humidity under a $12: 12$ photoperiod and are presumed mated.

\section{dsRNA knockdown}

RNAi was performed using 7 transcription factors based on previous publication of knockdown (Maf-s, Met, Dm (Ingham et al., 2018, Ingham et al., 2017)) or through random selection using a random number generator (Med, Pan, 1(1)sc, mbf1) (Supplementary Table 5). PCR was performed on 3-day old VK7 unexposed cDNA using Phusion ${ }^{\circledR}$ High-Fidelity DNA Polymerase (Thermo Scientific) following manufacturer's instructions and primer sets with a T7 docking sequence at the $5^{\prime}$ end of both the sense and antisense primers (Supplementary Table 5). Primers were designed as previously described (Ingham et al., 2018). PCR was performed using the following cycles: $98^{\circ} \mathrm{C}$ for $30 \mathrm{~s},\left(98^{\circ} \mathrm{C} 7 \mathrm{~s}\right.$, $65^{\circ} \mathrm{C} 10 \mathrm{~s}, 72^{\circ} \mathrm{C} 10 \mathrm{~s}$ ) $\mathrm{x} 35$ and $72^{\circ} \mathrm{C} 5$ minutes. PCR product was then purified using a Qiagen QIAquick PCR Purification Kit following manufacturers' instructions. dsRNA was then synthesised using a Megascript ${ }^{\circledR} \mathrm{T} 7$ Transcription (Ambion) kit, following manufacturer's instructions (16hour $37^{\circ} \mathrm{C}$ incubation). The dsRNA was cleaned using a MegaClear ${ }^{\circledR}$ Transcription Clear Up (Ambion) kit, with DEPC water, twice heated at $65^{\circ} \mathrm{C}$ for $10 \mathrm{~min}$, to elute the sample. The resultant dsRNA product was analysed using a nanodrop spectrometer (Nanodrop Technologies, UK) and subsequently concentrated to $3 \mu \mathrm{g} / \mu \mathrm{l}$ using a vacuum centrifuge at $35^{\circ} \mathrm{C}$. $69 \mathrm{~nL}$ of dsRNA was subsequently injected into presumed mated, non-blood fed, 3-day old VK7 females immobilised using a $\mathrm{CO}_{2}$ block using a NanoInject II. 50 females were injected with each of the transcription factor dsRNA and 50 with dsGFP as a non-endogenous control.

\section{Insecticide Exposures}

25-30 female mosquitoes were exposed to $0.05 \%$ deltamethrin impregnated papers for one hour in a standard tube bioassay kit following WHO guidelines. Post-exposure mosquitoes were transferred into holding tubes and maintained on sucrose solution.

\section{RNA extraction and cDNA synthesis}

RNA was extracted from 7-10 female mosquitoes in biological triplicate for each experimental group. RNA was extracted from homogenised mosquitoes using a PicoPure RNA isolation kit (Thermo Fisher, UK) following manufacturers' instructions and treated with DNAase (Qiagen) to remove any DNA contamination. Quality of RNA was checked using a nanodrop spectrophotometer (Nanodrop Technologies UK). 1$4 \mu \mathrm{g}$ of RNA from each experimental set was reversed transcribed using OligoDTT (Invitrogen) and Superscript III (Invitrogen) according to manufacturers' instructions. The following experimental groups were used: (i) knockdown efficacy for each transcription factor and the GFP 
control using females 48-hours post RNAi injection and (ii) pathway validation using females 48-hours after they were exposed to $0.05 \%$ deltamethrin for 48-hours post-injection for transcription factors and GFP controls.

\section{qPCR validation}

Quantitative real-time PCR was performed using SYBR Green Supermix III (Applied Biosystems, UK) using an MX3005 and the associated MxPro software v4.10 (Agilent, UK). Primer Blast (NCBI) was used to design primer pairs. Where possible, primers were designed to span an exon junction (Supplementary Table 5). Each $20 \mu 1$ reaction contained $10 \mu \mathrm{l}$ SYBR Green Supermix, $0.3 \mu \mathrm{M}$ of each primer and $1 \mu \mathrm{l}$ of $4 \mathrm{ng} / \mu \mathrm{L}$ cDNA. Standard curves for each primer set were used to calculate efficiency, using five 1:5 dilutions of cDNA to ensure that all primer sets met the MIQE guidelines (90-120\% efficiency) (Bustin et al., 2009). qPCR was performed with the following conditions: 3 minutes at $95^{\circ} \mathrm{C}$, with 40 cycles of 10 seconds at $95^{\circ} \mathrm{C}$ and 10 seconds at $60^{\circ} \mathrm{C}$. Relative expression was normalised against two housekeeping genes: EF (AGAP005128) and S7 (AGAP010592) and analysed using comparative CT method (Schmittgen and Livak, 2008). qPCR was used to determine the efficacy of transcription factor knockdown by comparing cDNA taken from mosquitoes 48-hours post dsRNA injection for each transcription factor and comparing it to GFP-injected controls all taken from the same mosquito generation. To validate findings in the network, qPCR was performed on dsRNA injected mosquitoes exposed to $0.05 \%$ deltamethrin at 48-hours post injection, these mosquitoes were then left for a further 48-hours before harvesting; again, transcription factor injected mosquitoes were compared to the dsGFP injected controls.

\section{Author Contributions}

VAI and FD designed and implemented the experiment. SCN performed the SILGGM analysis, FD modified and implemented the dynamic Bayesian network, SE provided rearing, bioassay and molecular biology support, VAI performed the lab-based experiments and analysed all data. VAI and FD drafted the manuscript.

\section{Data Availability}

The datasets used in this experiment are available at ArrayExpress under E-MTAB-9422 and E-MTAB-9423. The authors declare that all other data supporting the findings of this study, are available within the article and its Supplementary Information files or are available from the authors upon request.

\section{Code Availability}

Code used for analysis in this study is available on GitHub. Network visualisation is available at https://github.com/VictoriaIngham/NetworkVis_TimeCourse, model code is available on the CRAN repository: https://cran.rproject.org/web/packages/EDISON and full analysis is available at https://github.com/FrankD/AnophelesInsecticideExposure.

\section{Declaration of Competing Interest}

The authors declare that they have no known competing financial interests or personal relationships that could have appeared to influence the work reported in this paper.

\section{Acknowledgements}

This work was supported by a Medical Research Council Skills Development Fellowship [MR/R024839/1] to VAI. We thank Hilary Ranson and David Weetman for valuable feedback on the manuscript and Jessica Carson, Marion Morris and Ruth Cowlishaw for insectary support.

\section{Supplementary materials}

Supplementary material associated with this article can be found, in the online version, at doi:10.1016/j.cris.2021.100018.

\section{References}

Adryan, B, Teichmann, SA., 2006. FlyTF: a systematic review of site-specific transcription factors in the fruit fly Drosophila melanogaster. Bioinformatics 22, 1532-1533.

Almende B V, Thieurmel B, Robert T. visNetwork: Network Visualization using vis. js Library R package version 2.0. 4. 2018.

Amenya, DA, Chou, W, Li, J, Yan, G, Gershon, PD, James, AA, et al., 2010. Proteomics reveals novel components of the Anopheles gambiae eggshell. J Insect Physiol 56, 1414-1419. doi:10.1016/j.jinsphys.2010.04.013, doi:https://doi.org/.

Arbouzova, NI, Bach, EA, Zeidler, MP., 2006. Ken \& Barbie Selectively Regulates the Expression of a Subset of JAK/STAT Pathway Target Genes. Curr Biol 16, 80-88. doi:10.1016/j.cub.2005.11.033.

Ashburner, M, Ball, CA, Blake, JA, Botstein, D, Butler, H, Cherry, JM., 2000. Gene ontology: tool for the unification of biology. The gene ontology consortium. Nat Genet 25. doi:10.1038/75556.

Astigarraga, S, Grossman, R, Díaz-Delfín, J, Caelles, C, Paroush, Z, Jiménez, G., 2007. A MAPK docking site is critical for downregulation of Capicua by Torso and EGFR RTK signaling. EMBO J 26, 668-677. doi:10.1038/sj.emboj.7601532.

Athanasopoulos, V, Barker, A, Yu, D, Tan, AH, Srivastava, M, Contreras, N, et al., 2010. The ROQUIN family of proteins localizes to stress granules via the ROQ domain and binds target mRNAs. FEBS J 277, 2109-2127.

Balabanidou, V, Kampouraki, A, MacLean, M, Blomquist, GJ, Tittiger, C, Juárez, MP, et al., 2016. Cytochrome P450 associated with insecticide resistance catalyzes cuticular hydrocarbon production in Anopheles gambiae. Proc Natl Acad Sci doi:10.1073/pnas.1608295113.

Balabanidou, V, Kefi, M, Aivaliotis, M, Koidou, V, Girotti, JR, Mijailovsky, SJ, et al., 2019. Mosquitoes cloak their legs to resist insecticides. Proc R Soc B 286, 20191091.

Baqri, RM, Pietron, A V, Gokhale, RH, Turner, BA, Kaguni, LS, Shingleton, AW, et al., 2014. Mitochondrial chaperone TRAP1 activates the mitochondrial UPR and extends healthspan in Drosophila. Mech Ageing Dev doi:10.1016/j.mad.2014.09.002, 141142:35-45doi:https://doi.org/.

Barry, WE, Thummel, CS., 2016. The Drosophila HNF4 nuclear receptor promotes glucosestimulated insulin secretion and mitochondrial function in adults. Elife 5, e11183. doi:10.7554/eLife.11183.

Beller, M, Bulankina, A V, Hsiao, H-H, Urlaub, H, Jäckle, H, Kühnlein, RP., 2010. PERILIPIN-Dependent Control of Lipid Droplet Structure and Fat Storage in Drosophila. Cell Metab 12, 521-532. doi:10.1016/j.cmet.2010.10.001, doi:https://doi.org/.

Bharucha, KN, Tarr, P, Zipursky, SL., 2008. A glucagon-like endocrine pathway in Drosophila modulates both lipid and carbohydrate homeostasis. J Exp Biol 211. doi:10.1242/jeb.016451, 3103 LP -3110.

Bhatt, S, Weiss, DJ, Cameron, E, Bisanzio, D, Mappin, B, Dalrymple, U, et al., 2015. The effect of malaria control on Plasmodium falciparum in Africa between 2000 and 2015 Nature 526, 207-211.

Blanco, J, Cooper, JC, Baker, NE., 2020. Roles of C/EBP class bZip proteins in the growth and cell competition of Rp ('Minute') mutants in Drosophila. Elife 9, e50535. doi:10.7554/eLife.50535.

Bottino-Rojas, V, Talyuli, OAC, Carrara, L, Martins, AJ, James, AA, Oliveira, PL, et al., 2018. The redox-sensing gene Nrf2 affects intestinal homeostasis, insecticide resistance, and Zika virus susceptibility in the mosquito Aedes aegypti. J Biol Chem 293, 9053-9063.

Brodsky, MH, Weinert, BT, Tsang, G, Rong, YS, McGinnis, NM, Golic, KG, et al., 2004. Drosophila melanogaster MNK/Chk2 and p53 Regulate Multiple DNA Repair and Apoptotic Pathways following DNA Damage. Mol Cell Biol 24. doi:10.1128/MCB.24.3.1219-1231.2004, 1219 LP -1231.

Brunner, E, Peter, O, Schweizer, L, Basler, K., 1997. pangolinencodes a Lef-1 homologue that acts downstream of Armadillo to transduce the Wingless signal in Drosophila. Nature 385, 829-833. doi:10.1038/385829a0.

Bustin, SA, Benes, V, Garson, JA, Hellemans, J, Huggett, J, Kubista, M, et al., 2009. The MIQE guidelines: minimum information for publication of quantitative real-time PCR experiments. Clin Chem 55, 611-622.

Carlson M, Pagès H. AnnotationForge: Tools for building SQLite-Based Annotation Data Packages, 2019. R Packag version. 1.

Chang W, Cheng J, Allaire J, Xie Y, McPherson J. shiny: Web Application Framework for R. 2017. https://cran.r-project.org/package=shiny.

Chen, J V, Kao, L-R, SC, Jana, Sivan-Loukianova, E, Mendonça, S, Cabrera, OA, et al., 2015. Rootletin organizes the ciliary rootlet to achieve neuron sensory function in Drosophila. J Cell Biol 211, 435-453. doi:10.1083/jcb.201502032.

Chen, J, Shi, X, Padmanabhan, R, Wang, Q, Wu, Z, Stevenson, SC, et al., 2008. Identification of novel modulators of mitochondrial function by a genome-wide RNAi screen in Drosophila melanogaster. Genome Res 18, 123-136.

Chen, T-H, Wu, Y-J, Hou, J-N, Chiu, C-H, Chen, W-J., 2017. The p53 gene with emphasis on its paralogues in mosquitoes. J Microbiol Immunol Infect 50, 747-754. doi:10.1016/j.jmii.2017.06.006, doi:https://doi.org/.

Chowdhury A, Modahl CM, Tan ST, Xiang BWW, Missé D, Vial T, et al. JNK pathway restricts DENV, ZIKV and CHIKV infection by activating complement and apoptosis in mosquito salivary glands. bioRxiv. 2020;:2020.03.01.972026. doi:10.1101/2020.03.01.972026. 
Cleveland, WS, Grosse, E, Shyu, WM., 1992. Local regression models. Chapter 8 in Statistical models in S. Wadsworth Brooks/Cole, Pacific Grove, CA, p. 608 JM Chambers and TJ Hastie eds.

Consortium, F., 2003. The FlyBase database of the Drosophila genome projects and community literature. Nucleic Acids Res 31, 172-175.

Cornelissen, T, Vilain, S, Vints, K, Gounko, N, Verstreken, P, Vandenberghe, W., 2018. Deficiency of parkin and PINK1 impairs age-dependent mitophagy in Drosophila. Elife 7, e35878.

Csardi, G, Nepusz, T., 2006. The igraph software package for complex network research. InterJournal, complex Syst 1695, 1-9.

Delgado, FM, Gómez-Vela, F., 2019. Computational methods for Gene Regulatory Networks reconstruction and analysis: A review. Artif Intell Med 95, 133-145.

Dondelinger, F, Lèbre, S, Husmeier, D., 2013. Non-homogeneous dynamic Bayesian networks with Bayesian regularization for inferring gene regulatory networks with gradually time-varying structure. Mach Learn 90, 191-230.

Dondelinger, F, Mukherjee, S., 2019. Statistical network inference for time-varying molecular data with dynamic bayesian networks. In: Gene regulatory networks. Springer, pp. 25-48.

Dushay, MS, Asling, B, Hultmark, D., 1996. Origins of immunity: Relish, a compound Rel-like gene in the antibacterial defense of Drosophila. Proc Natl Acad Sci 93. doi:10.1073/pnas.93.19.10343, 10343 LP -10347.

Félix, JT, Magariños, M, Díaz-Benjumea, FJ., 2007. Nab controls the activity of the zincfinger transcription factors Squeeze and Rotund in Drosophila development. Development. 134. doi:10.1242/dev.003830, 1845 LP -1852.

Fu, X, Liu, P, Dimopoulos, G, Zhu, J., 2020. Dynamic miRNA-mRNA interactions coordinate gene expression in adult Anopheles gambiae. PLOS Genet 16, e1008765. doi:10.1371/journal.pgen.1008765

Gaddelapati, SC, Kalsi, M, Roy, A, Palli, SR., 2018. Cap'n'collar C regulates genes responsible for imidacloprid resistance in the Colorado potato beetle, Leptinotarsa decemlineata. Insect Biochem Mol Biol 99, 54-62.

Gellatly, KJ, Yoon, KS, Doherty, JJ, Sun, W, Pittendrigh, BR, Clark, JM., 2015. RNAi validation of resistance genes and their interactions in the highly DDT-resistant 91-R strain of Drosophila melanogaster. Pestic Biochem Physiol 121, 107-115.

Giraldo-Calderón, GI, Emrich, SJ, MacCallum, RM, Maslen, G, Dialynas, E, Topalis, P, et al., 2014. VectorBase: an updated bioinformatics resource for invertebrate vectors and other organisms related with human diseases. Nucleic Acids Res 43, D707-D713.

Gross, I, Georgel, P, Oertel-Buchheit, P, Schnarr, M, Reichhart, J-M., 1999. Dorsal-B, a splice variant of the Drosophila factor Dorsal, is a novel Rel/NF- $\kappa$ B transcriptional activator1The sequence described in this paper was deposited in GeneBank under the Accession No. AF053614.1. Gene 228, 233-242. doi:10.1016/S0378-1119(98)00595-2, doi:https://doi.org/

Hamann, S, Strätling, WH., 1998. Specific binding of Drosophila nuclear protein PEP (protein on ecdysone puffs) to hsp70 DNA and RNA. Nucleic Acids Res 26, 4108-4115. doi:10.1093/nar/26.18.4108.

Hawley, WA, Phillips-Howard, PA, ter Kuile, FO, Terlouw, DJ, Vulule, JM, Ombok, M, et al., 2003. Community-wide effects of permethrin-treated bed nets on child mortality and malaria morbidity in western Kenya. Am J Trop Med Hyg 68 (4 Suppl), 121-127.

Herold, N, Will, CL, Wolf, E, Kastner, B, Urlaub, H, Lührmann, R., 2009. Conservation of the Protein Composition and Electron Microscopy Structure of Drosophila melanogaster and Human Spliceosomal Complexes. Mol Cell Biol 29 (281). doi:10.1128/MCB.01415-08, LP -301

Hong, S-T, Choi, K-W., 2013. TCTP directly regulates ATM activity to control genome stability and organ development in Drosophila melanogaster. Nat Commun 4, 1-14.

Hsia, CC, McGinnis, W., 2003. Evolution of transcription factor function. Curr Opin Genet Dev 13, 199-206. doi:10.1016/S0959-437X(03)00017-0, doi:https://doi.org/.

Hu, B, Huang, H, Wei, Q, Ren, M, Mburu, DK, Tian, X, et al., 2019. Transcription factors $\mathrm{CncC} / \mathrm{Maf}$ and AhR/ARNT coordinately regulate the expression of multiple GSTs conferring resistance to chlorpyrifos and cypermethrin in Spodoptera exigua. Pest Manag Sci 75, 2009-2019. doi:10.1002/ps.5316.

Hughes, A, Lissenden, N, Viana, M, Toe, KH, Ranson, H., 2020. Anopheles gambiae populations from Burkina Faso show minimal delayed mortality after exposure to insecticide-treated nets. Parasit Vectors 13, 17

Ingham VA, Brown F, Ranson H. Sub-lethal pyrethroid exposure and ageing lead to pronounced changes in gene expression in insecticide resistance Anopheles coluzziibioRxiv. 2020;:2020.08.14.250852. doi:10.1101/2020.08.14.250852.

Ingham, VA, Pignatelli, P, Moore, JD, Wagstaff, S, Ranson, H., 2017. The transcription factor Maf-S regulates metabolic resistance to insecticides in the malaria vector Anopheles gambiae. BMC Genomics 18.

Ingham, VA, Wagstaff, S, Ranson, H., 2018. Transcriptomic meta-signatures identified in Anopheles gambiae populations reveal previously undetected insecticide resistance mechanisms. Nat Commun 9, 5282. doi:10.1038/s41467-018-07615-x.

Ingham, VAVA, Anthousi, A, Douris, V, Harding, NJNJ, Lycett, G, Morris, M, et al., 2019. A sensory appendage protein protects malaria vectors from pyrethroids. Nature 577. doi:10.1038/s41586-019-1864-1.

Iyer, EPR, Iyer, SC, Sullivan, L, Wang, D, Meduri, R, Graybeal, LL, et al., 2013. Functional Genomic Analyses of Two Morphologically Distinct Classes of Drosophila Sensory Neurons: Post-Mitotic Roles of Transcription Factors in Dendritic Patterning. PLoS One 8, e72434. doi:10.1371/journal.pone.0072434.

Jackson, CA, Castro, DM, Saldi, G-A, Bonneau, R, Gresham, D., 2020. Gene regulatory network reconstruction using single-cell RNA sequencing of barcoded genotypes in diverse environments. Elife 9, e51254.

Janková, J, van de Geer, S., 2017. Honest confidence regions and optimality in high-dimensional precision matrix estimation. Test 26, 143-162.

Janková J, van de Geer S. Inference in high-dimensional graphical models. arXiv Prepr arXiv180108512. 2018.
Jassal, B, Matthews, L, Viteri, G, Gong, C, Lorente, P, Fabregat, A, et al., 2020. The reactome pathway knowledgebase. Nucleic Acids Res 48, D498-D503.

Jindra, M, Gaziova, I, Uhlirova, M, Okabe, M, Hiromi, Y, Hirose, S., 2004. Coactivator MBF1 preserves the redox-dependent AP-1 activity during oxidative stress in Drosophila. EMBO J 23, 3538-3547.

Jindra, M, Uhlirova, M, Charles, J-P, Smykal, V, Hill, RJ., 2015. Genetic Evidence for Function of the bHLH-PAS Protein Gce/Met As a Juvenile Hormone Receptor. PLOS Genet 11, e1005394. doi:10.1371/journal.pgen.1005394.

Jones, CM, Sanou, A, Guelbeogo, WM, Sagnon, N, Johnson, PCD, Ranson, H., 2012. Aging partially restores the efficacy of malaria vector control in insecticideresistant populations of Anopheles gambiae s.l. from Burkina Faso. Malar J 11, 24. doi:10.1186/1475-2875-11-24.

Kalsi, M, Palli, SR., 2015. Transcription factors, CncC and Maf, regulate expression of CYP6BQ genes responsible for deltamethrin resistance in Tribolium castaneum. Insect Biochem Mol Biol 65, 47-56.

Kanehisa, M, Goto, S., 2000. KEGG: kyoto encyclopedia of genes and genomes. Nucleic Acids Res 28, 27-30.

Kappes, G, Deshpande, G, Mulvey, BB, Horabin, JI, Schedl, P., 2011. The Drosophila Myc gene, diminutive, is a positive regulator of the Sex-lethal establishment promoter, Sxl-Pe. Proc Natl Acad Sci 108, 1543-1548.

Kavaler, J, Fu, W, Duan, H, Noll, M, Posakony, JW., 1999. An essential role for the Drosophila Pax2 homolog in the differentiation of adult sensory organs. Development 126. 2261 LP -2272 http://dev.biologists.org/content/126/10/2261.abstract

Killeen, GF, Okumu, FO, N'Guessan, R, Coosemans, M, Adeogun, A, Awolola, S, et al., 2011. The importance of considering community-level effects when selecting insecticidal malaria vector products. Parasit Vectors 4, 160.

Killeen, GF, Smith, TA., 2007. Exploring the contributions of bed nets, cattle, insecticides and excitorepellency to malaria control: a deterministic model of mosquito host-seeking behaviour and mortality. Trans R Soc Trop Med Hyg 101, 867-880. doi:10.1016/j.trstmh.2007.04.022.

Koch, I, Schwarz, H, Beuchle, D, Goellner, B, Langegger, M, Aberle, H., 2008. Drosophila ankyrin 2 is required for synaptic stability. Neuron 58, 210-222.

Lee, JC, VijayRaghavan, K, Celniker, SE, Tanouye, MA., 1995. Identification of a Drosophila muscle development gene with structural homology to mammalian early growth response transcription factors. Proc Natl Acad Sci 92 doi:10.1073/pnas.92.22.10344, 10344 LP -10348.

Li, A, Hooli, B, Mullin, K, Tate, RE, Bubnys, A, Kirchner, R, et al., 2017. Silencing of the Drosophila ortholog of SOX5 leads to abnormal neuronal development and behavioral impairment. Hum Mol Genet 26, 1472-1482. doi:10.1093/hmg/ddx051.

Li, C, Harding, GA, Parise, J, McNamara-Schroeder, KJ, Stumph, WE., 2004. Architectural Arrangement of Cloned Proximal Sequence Element-Binding Protein Subunits on Drosophila U1 and U6 snRNA Gene Promoters. Mol Cell Biol 24. doi:10.1128/MCB.24.5.1897-1906.2004, 1897 LP -1906.

Luna, C, Hoa, NT, Lin, H, Zhang, L, Nguyen, HLA, Kanzok, SM, et al., 2006. Expression of immune responsive genes in cell lines from two different Anopheline species. Insect Mol Biol 15, 721-729. doi:10.1111/j.1365-2583.2006.00661.x.

Lyne, R, Smith, R, Rutherford, K, Wakeling, M, Varley, A, Guillier, F, et al., 2007. FlyMine: An Integrated Database for Drosophila and Anopheles Genomics. Genome Biol C7 R129 8, 1-16. doi:10.1186/gb-2007-8-7-r129, LA-English.

Maliti, DV, Marsden, CD, Main, BJ, Govella, NJ, Yamasaki, Y, Collier, TC, et al., 2016. Investigating associations between biting time in the malaria vector Anopheles arabiensis Patton and single nucleotide polymorphisms in circadian clock genes: support for sub-structure among An. arabiensis in the Kilombero valley of Tanzania. Parasit Vectors 9, 109. doi:10.1186/s13071-016-1394-8.

Martinez-Torres, D, Chandre, F, Williamson, MS, Darriet, F, Berge, JB, Devonshire, AL, et al., 1998. Molecular characterization of pyrethroid knockdown resistance (kdr) in the major malaria vector Anopheles gambiae ss. Insect Mol Biol 7, 179-184.

Melcher, C, Pankratz, MJ., 2005. Candidate gustatory interneurons modulating feeding behavior in the Drosophila brain. PLoS Biol 3, e305.

Miotto, B, Sagnier, T, Berenger, H, Bohmann, D, Pradel, J, Graba, Y., 2006. Chameau HAT and DRpd3 HDAC function as antagonistic cofactors of JNK/AP-1-dependent transcription during Drosophila metamorphosis. Genes Dev 20, 101-112.

Misra, JR, Horner, MA, Lam, G, Thummel, CS., 2011. Transcriptional regulation of xenobiotic detoxification in Drosophila. Genes Dev 25, 1796-1806.

Moloney, DJ, Panin, VM, Johnston, SH, Chen, J, Shao, L, Wilson, R, et al., 2000. Fringe is a glycosyltransferase that modifies Notch. Nature 406, 369-375.

Morrison, HA, Dionne, H, Rusten, TE, Brech, A, Fisher, WW, Pfeiffer, BD, et al., 2008. Regulation of early endosomal entry by the Drosophila tumor suppressors Rabenosyn and Vps45. Mol Biol Cell 19, 4167-4176. doi:10.1091/mbc.e08-07-0716.

Müller, P, Warr, E, Stevenson, BJ, Pignatelli, PM, Morgan, JC, Steven, A, et al., 2008. Field-Caught Permethrin-Resistant Anopheles gambiae Overexpress CYP6P3, a P450 That Metabolises Pyrethroids. PLoS Genet 4, e1000286. doi:10.1371/journal.pgen.1000286, http://dx.doi.org/.

Mundorf, J, Donohoe, CD, McClure, CD, Southall, TD, Uhlirova, M. 2019. Ets21c Governs Tissue Renewal, Stress Tolerance, and Aging in the $<\mathrm{em}>$ Drosophila $</$ em $>$ Intestine. Cell Rep 27, 3019-3033. doi:10.1016/j.celrep.2019.05.025, e5.

Murata, H, Takamatsu, H, Liu, S, Kataoka, K, Huh, N, Sakaguchi, M., 2015. NRF2 Regulates PINK1 Expression under Oxidative Stress Conditions. PLoS One 10, e0142438. doi:10.1371/journal.pone.0142438, https://doi.org/.

Murphy, K, Mian, S., 1999. Modelling gene expression data using dynamic Bayesian networks. Citeseer;

Musselman, LP, Fink, JL, Maier, EJ, Gatto, JA, Brent, MR, Baranski, TJ., 2018. Seven-up is a novel regulator of insulin signaling. Genetics 208, 1643-1656. 
Nagy, P, Varga, A, Pircs, K, Hegedús, K, Juhász, G., 2013. Myc-driven overgrowth requires unfolded protein response-mediated induction of autophagy and antioxidant responses in Drosophila melanogaster. PLoS Genet 9.

$\mathrm{Ng}$, J, Luo, L., 2004. Rho GTPases regulate axon growth through convergent and divergent signaling pathways. Neuron 44, 779-793.

Oliver, S V, Brooke, BD., 2016. The Role of Oxidative Stress in the Longevity and Insecticide Resistance Phenotype of the Major Malaria Vectors Anopheles arabiensis and Anopheles funestus. PLoS One 11, e0151049 http://dx.doi.org/10.1371\%2Fjournal.pone.0151049.

Palanker, L, Tennessen, JM, Lam, G, Thummel, CS., 2009. <em > Drosophila </em > HNF4 Regulates Lipid Mobilization and $\beta$-Oxidation. Cell Metab 9, 228-239. doi:10.1016/j.cmet.2009.01.009.

Panara, V, Budd, GE, Janssen, R., 2019. Phylogenetic analysis and embryonic expression of panarthropod Dmrt genes. Front Zool 16, 23. doi:10.1186/s12983-019-0322-0.

Papagianni, A, Forés, M, Shao, W, He, S, Koenecke, N, Andreu, MJ, et al., 2018. Capicua controls Toll/IL-1 signaling targets independently of RTK regulation. Proc Natl Acad Sci 115. doi:10.1073/pnas.1713930115, 1807 LP -1812.

Papoulas, O, Daubresse, G, Armstrong, JA, Jin, J, Scott, MP, Tamkun, JW, 2001. The HMG-domain protein BAP111 is important for the function of the BRM chromatinremodeling complex in vivo. Proc Natl Acad Sci. 98. doi:10.1073/pnas.091533398, 5728 LP -5733

Parisi, F, Riccardo, S, Zola, S, Lora, C, Grifoni, D, Brown, LM, et al., 2013. dMyc expression in the fat body affects DILP2 release and increases the expression of the fat desaturase Desat1 resulting in organismal growth. Dev Biol 379, 64-75. doi:10.1016/j.ydbio.2013.04.008, doi:https://doi.org/.

Pecasse, F, Beck, Y, Ruiz, C, Richards, G., 2000. Krüppel-homolog, a stage-specific modulator of the prepupal ecdysone response, is essential for Drosophila metamorphosis. Dev Biol 221, 53-67.

Peng, T, Chen, X, Pan, Y, Zheng, Z, Wei, X, Xi, J, et al., 2017. Transcription factor aryl hydrocarbon receptor/aryl hydrocarbon receptor nuclear translocator is involved in regulation of the xenobiotic tolerance-related cytochrome P450 CYP6DA2 in Aphis gossypii Glover. Insect Mol Biol.

Piacentini, L, Fanti, L, Berloco, M, Perrini, B, Pimpinelli, S., 2003. Heterochromatin protein 1 (HP1) is associated with induced gene expression in Drosophila euchromatin. J Cell Biol 161, 707-714. doi:10.1083/jcb.200303012.

Pignatelli, P, Ingham, VAA, Balabanidou, V, Vontas, J, Lycett, G, Ranson, H., 2018. The Anopheles gambiae ATP-binding cassette transporter family: phylogenetic analysis and tissue localization provide clues on function and role in insecticide resistance. Insect Mol Biol 27, 110-122. doi:10.1111/imb.12351.

Popp, J, Petô, K, Nagy, J., 2013. Pesticide productivity and food security. A review. Agron Sustain Dev 33, 243-255. doi:10.1007/s13593-012-0105-x.

Protzer, CE, Wech, I, Nagel, AC., 2008. Hairless induces cell death by downregulation of EGFR signalling activity. J Cell Sci 121. doi:10.1242/jcs.035014, 3167 LP -3176.

Rämet, M, Lanot, R, Zachary, D, Manfruelli, P., 2002. JNK Signaling Pathway Is Required for Efficient Wound Healing in Drosophila. Dev Biol 241, 145-156. doi:10.1006/dbio.2001.0502, doi:https://doi.org/.

Reddy, BA, Bajpe, PK, Bassett, A, Moshkin, YM, Kozhevnikova, E, Bezstarosti, K, et al., 2010. Drosophila transcription factor Tramtrack69 binds MEP1 to recruit the chromatin remodeler NuRD. Mol Cell Biol 30, 5234-5244.

Riveron, JM, Yunta, C, Ibrahim, SS, Djouaka, R, Irving, H, Menze, BD, et al., 2014. A single mutation in the GSTe2 gene allows tracking of metabolically based insecticide resistance in a major malaria vector. Genome Biol 15, R27.

Ruiz, JL, Yerbanga, RS, Lefèvre, T, Ouedraogo, JB, Corces, VG, Gómez-Díaz, E., 2019. Chromatin changes in Anopheles gambiae induced by Plasmodium falciparum infection. Epigenetics Chromatin 12, 5. doi:10.1186/s13072-018-0250-9.

Rund, SSC, Hou, TY, Ward, SM, Collins, FH, Duffield, GE., 2011. Genome-wide profiling of diel and circadian gene expression in the malaria vector Anopheles gambiae. Proc Natl Acad Sci 108. doi:10.1073/pnas.1100584108, E421 LP-E430.

Rund, SSC, O'Donnell, AJ, Gentile, JE, Reece, SE, 2016. Daily rhythms in mosquitoes and their consequences for malaria transmission. Insects 7, 14.

Rutila, JE, Suri, V, Le, M, So, WV, Rosbash, M, Hall, JC., 1998. CYCLE Is a Second bHLH-PAS Clock Protein Essential for Circadian Rhythmicity and Transcription of $<$ em $>$ Drosophila period $</$ em $>$ and $<$ em $>$ timeless $</$ em $>$. Cell 93, 805-814. doi:10.1016/S0092-8674(00)81441-5.

Schaefer, M, Petronczki, M, Dorner, D, Forte, M, Knoblich, JA., 2001. Heterotrimeric G proteins direct two modes of asymmetric cell division in the Drosophila nervous system. Cell 107, 183-194.
Schmittgen, TD, Livak, KJ., 2008. Analyzing real-time PCR data by the comparative CT method. Nat Protoc 3, 1101-1108.

Shannon, P, Markiel, A, Ozier, O, Baliga, NS, Wang, JT, Ramage, D, et al., 2003. Cytoscape: a software environment for integrated models of biomolecular interaction networks. Genome Res 13, 2498-2504.

Stagg, SB, Guardiola, AR, Crews, ST., 2011. Dual role for Drosophila lethal of scute in CNS midline precursor formation and dopaminergic neuron and motoneuron cell fate. Development 138. doi:10.1242/dev.056507, 2171 LP -2183.

Taylor-Wells, J, Brooke, BD, Bermudez, I, Jones, AK., 2015. The neonicotinoid imidacloprid, and the pyrethroid deltamethrin, are antagonists of the insect Rdl GABA receptor. J Neurochem doi:10.1111/jnc.13290, n/a-n/a.

Tearle, R, Tomlinson, A, Saint, R., 1994. The dominant Drop eye mutations of Drosophila melanogaster define two loci implicated in normal eye development. Mol Gen Genet MGG 244, 426-434. doi:10.1007/BF00286695.

Terriente-Félix, A, de Celis, JF., 2009. Osa, a subunit of the BAP chromatin-remodelling complex, participates in the regulation of gene expression in response to EGFR signalling in the Drosophila wing. Dev Biol 329, 350-361.

Thompson, D, Regev, A, Roy, S., 2015. Comparative analysis of gene regulatory networks: from network reconstruction to evolution. Annu Rev Cell Dev Biol 31, 399-428.

Toé, KH, N'Falé, S, Dabiré, RK, Ranson, H, Jones, CM, 2015. The recent escalation in strength of pyrethroid resistance in Anopheles coluzzi in West Africa is linked to increased expression of multiple gene families. BMC Genomics 16, 146.

Varghese, J, Lim, SF, Cohen, SM., 2010. Drosophila miR-14 regulates insulin production and metabolism through its target, sugarbabe. Genes Dev 24, 2748-2753.

Voice, MW, Kaaz, AW, Peet, CF, Paine, MJ., 2015. Recombinant CYP6M2 Inhibition by Insecticides Recommended by WHO for Indoor Residual Spraying Against Malaria Vectors. Drug Metab Rev 44, 56-57.

Voßfeldt, H, Butzlaff, M, Prüßing, K, Chárthaigh, R-AN, Karsten, P, Lankes, A, et al., 2012. Large-scale screen for modifiers of ataxin-3-derived polyglutamine-induced toxicity in Drosophila. PLoS One 7, e47452.

Wang, X, Hou, Y, Saha, TT, Pei, G, Raikhel, AS, Zou, Z., 2017. Hormone and receptor interplay in the regulation of mosquito lipid metabolism. Proc Natl Acad Sci 114, E2709-E2718. doi:10.1073/pnas.1619326114.

Wang, X, Martínez, M-A, Dai, M, Chen, D, Ares, I, Romero, A, et al., 2016. Permethrininduced oxidative stress and toxicity and metabolism. A review. Environ Res 149, 86-104. doi:10.1016/j.envres.2016.05.003, doi:https://doi.org/.

Weill, M, Malcolm, C, Chandre, F, Mogensen, K, Berthomieu, A, Marquine, M, et al., 2004. The unique mutation in ace- 1 giving high insecticide resistance is easily detectable in mosquito vectors. Insect Mol Biol 13, 1-7. doi:10.1111/j.1365-2583.2004.00452.x.

WHO, 2020. World Malaria Report. WHO, Geneva.

Wilding, CS, Weetman, D, Rippon, EJ, Steen, K, Mawejje, HD, Barsukov, I, et al., 2014. Parallel evolution or purifying selection, not introgression, explains similarity in the pyrethroid detoxification linked GSTE4 of Anopheles gambiae and An. arabiensis. Mol Genet Genomics 1-15.

Williams, J, Flood, L, Praulins, G, Ingham, VA, Morgan, J, Lees, RS, et al., 2019. Characterisation of Anopheles strains used for laboratory screening of new vector control products. Parasit Vectors 12, 522. doi:10.1186/s13071-019-3774-3.

Wisotzkey, RG, Mehra, A, Sutherland, DJ, Dobens, LL, Liu, X, Dohrmann, C, et al., 1998. Medea is a Drosophila Smad4 homolog that is differentially required to potentiate DPP responses. Development 125, 1433-1445.

Wülbeck, C, Simpson, P., 2002. The expression of pannier and achaete-scute homologues in a mosquito suggests an ancient role of pannier as a selector gene in the regulation of the dorsal body pattern. Development 129. 3861 LP -3871 http://dev.biologists.org/content/129/16/3861.abstract .

Yan, H, Jahanshahi, M, Horvath, EA, Liu, H-Y, Pfleger, CM., 2010. Rabex-5 Ubiquitin Ligase Activity Restricts Ras Signaling to Establish Pathway Homeostasis in $<$ em > Drosophila</em > . Curr Biol 20, 1378-1382. doi:10.1016/j.cub.2010.06.058.

Yu, G, Wang, L-G, Han, Y, He, Q-Y., 2012. clusterProfiler: an R package for comparing biological themes among gene clusters. Omi a. J Integr Biol 16, 284-287.

Yunta, C, Hemmings, K, Stevenson, B, Koekemoer, LL, Matambo, T, Pignatelli, P, et al., 2019. Cross-resistance profiles of malaria mosquito P450s associated with pyrethroid resistance against WHO insecticides. Pestic Biochem Physiol doi:10.1016/j.pestbp.2019.06.007, doi:https://doi.org/.

Zhang, R, Ren, Z, Chen, W., 2018. SILGGM: An extensive R package for efficient statistical inference in large-scale gene networks. PLoS Comput Biol 14, e1006369.

Zhong Y, Wu C-F. Neuronal Activity and Adenylyl Cyclase in Environment-Dependent Plasticity of Axonal Outgrowth in Drosophila J Neurosci. 2004 ; 24 :1439 LP - 1445. doi:10.1523/JNEUROSCI.0740-02.2004. 